Portland State University

PDXScholar

\title{
Distressed and Distracted by COVID-19 During High- Stakes Virtual Interviews: the Role of Job Interview Anxiety on Performance and Reactions
}

Julie M. McCarthy

University of Toronto, Scarborough

Donald M. Truxillo

University of Limerick

Talya N. Bauer

Portland State University, talyabauer@pdx.edu

Berrin Erdogan

Portland State University, berrine@pdx.edu

Yiduo Shao

University of Florida

Follow this and additional works at: https://pdxscholar.library.pdx.edu/busadmin_fac

Part of the Business Commons

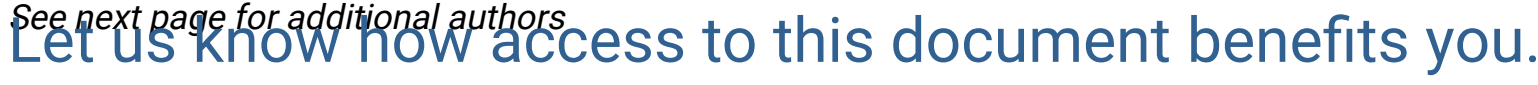

\section{Citation Details}

McCarthy, Julie M.; Truxillo, Donald M.; Bauer, Talya N.; Erdogan, Berrin; Shao, Yiduo; Wang, Mo; Liff, Joshua; and Gardner, Cari, "Distressed and Distracted by COVID-19 During High-Stakes Virtual Interviews: the Role of Job Interview Anxiety on Performance and Reactions" (2021). Business Faculty Publications and Presentations. 234.

https://pdxscholar.library.pdx.edu/busadmin_fac/234

This Post-Print is brought to you for free and open access. It has been accepted for inclusion in Business Faculty Publications and Presentations by an authorized administrator of PDXScholar. Please contact us if we can make this document more accessible: pdxscholar@pdx.edu. 


\section{Authors}

Julie M. McCarthy, Donald M. Truxillo, Talya N. Bauer, Berrin Erdogan, Yiduo Shao, Mo Wang, Joshua Liff, and Cari Gardner 
Distressed and Distracted by COVID-19 during High-Stakes Virtual Interviews:

The Role of Job Interview Anxiety on Performance and Reactions

\author{
Julie M. McCarthy \\ University of Toronto \\ Donald M. Truxillo \\ University of Limerick \\ Talya N. Bauer \\ Berrin Erdogan \\ Portland State University \\ Yiduo Shao \\ Mo Wang \\ University of Florida \\ Joshua Liff \\ Cari Gardner \\ HireVue
}

\begin{abstract}
Author Notes
This research was supported, in part, by research grants from the Social Sciences and Humanities Research Council of Canada awarded to Julie McCarthy (\#435-2015-0220) and the LanzillottiMcKethan Eminent Scholar Endowment awarded to Mo Wang. We thank Stefanie Fox for her valuable work as a research assistant.
\end{abstract}

Correspondence concerning this article should be addressed to Julie M. McCarthy, Department of Management, University of Toronto Scarborough, 1095 Military Trail, Toronto, ON M1C 1A4, Canada. Email: julie.mccarthy@utoronto.ca 


\begin{abstract}
Employers have increasingly turned to virtual interviews to facilitate online, socially distanced selection processes in the face of the COVID-19 pandemic. However, there is little understanding about the experience of job candidates in these virtual interview contexts. We draw from Event System Theory (Morgeson et al., 2015) to advance and test a conceptual model that focuses on a high-stress, high-stakes setting and integrates literatures on workplace stress with literatures on applicant reactions. We predict that when applicants ruminate about COVID-19 during an interview and have higher levels of COVID-19 exhaustion, they will have higher levels of anxiety during virtual interviews, which in turn relates to reduced interview performance, lower perceptions of fairness, and reduced intention to recommend the organization. Further, we predict that three factors capturing COVID-19 as an enduring and impactful event (COVID-19 duration, COVID-19 cases, COVID-19 deaths) will be positively related to COVID-19 exhaustion. We tested our propositions with 8,343 job applicants across 373 companies and 93 countries/regions. Consistent with predictions, we found a positive relationship between COVID-19 rumination and interview anxiety, and this relationship was stronger for applicants who experienced high (vs. low) levels of COVID-19 exhaustion. In turn, interview anxiety was negatively related to interview performance, fairness perceptions, and recommendation intentions. Moreover, using a relevant subset of the data $(n=6,136)$, we found that COVID-19 duration and deaths were positively related to COVID-19 exhaustion. This research offers several insights for understanding the virtual interview experience embedded in the pandemic and advances the literature on applicant reactions.
\end{abstract}

Keywords: COVID-19; anxiety; rumination; exhaustion; virtual interviews; interview performance 
Even before COVID-19, job applicant anxiety was common, with $73 \%$ of candidates reporting that the job search process is one of the most stressful things in life (CareerBuilder, 2017). On March 11, 2020, the World Health Organization (WHO) declared COVID-19 a pandemic. The pandemic resulted in massive layoffs, increased unemployment, and high levels of economic uncertainty (e.g., Eurostat, 2020; Kniffin et al., 2020; Maurer, 2021). This series of events heightened anxiety due to concerns regarding health and safety for oneself and others, ambiguity regarding established personal and work-related patterns of functioning, and apprehension regarding employment and financial stability. The stakes are high and for many applicants the path toward employment begins with an interview.

Although the study of interview anxiety and its implications for job applicants and organizations has never been more important, our understanding of this domain is relatively sparse even under normal circumstances. Not only do we know little about the factors that influence the experience of interview anxiety, but we also lack a solid understanding of the extent to which interview anxiety is related to outcomes that are important for applicants and organizations - namely interview performance, perceptions of fairness, and intention to recommend the organization. From the applicant's perspective, the competitive job market means that high performance in these stressful times is critical to securing a job. From the organization's perspective, it is important to ensure that candidates view the organization through a positive lens, as applicant reactions are related to organizational image, the hiring of top talent, and consumer purchase behaviors.

The present study advances both the anxiety and selection literatures. Drawing from Event System Theory (EST; Morgeson et al., 2015), we develop a conceptual model that focuses on a highstakes, high-stress context - applicants applying for jobs during the midst of a global pandemic. Our model also aligns with literatures on workplace stress and resource depletion (Bakker \& Demerouti, 
2007; Hobfoll, 1989) to explicate how applicants' feelings of anxiety during interviews are shaped by two variables concerning applicants' experiences specific to the pandemic context (i.e., COVID19 rumination and COVID-19 exhaustion), and the corresponding implications for applicant and organizational outcomes (see Figure 1). Our model predicts that when applicants ruminate about COVID-19 during their interviews and have higher levels of COVID-19 exhaustion, they will have higher levels of interview anxiety, which in turn relate to reduced interview performance, lower fairness perceptions, and reduced recommendation intentions. It further proposes that three variables aligned with EST - COVID-19 duration, COVID-19 cases, and COVID-19 deaths - will be associated with the experience of COVID-19 exhaustion.

Our research advances existing theory and research in three specific ways. First, it is one of the few studies to examine how interview anxiety relates to actual interview performance, fairness perceptions, and recommendation intentions in an actual hiring setting rather than in artificial research settings or using convenience samples with student populations. Indeed, nearly all of the research on interview anxiety has relied on scenario-based or lab studies using convenience samples (e.g., students) in which applicants do not experience an actual interview (Basch et al., 2019; Powell et al., 2018). This is primarily because data from actual applicants are difficult to obtain. Nevertheless, this gap is problematic, as existing findings may misrepresent the magnitude of the relationships found among actual applicants (Chapman et al., 2005; Truxillo et al., 2009), hindering the advancement of theoretical models that reflect reality and limiting practical application.

Second, our work is firmly situated within the context of the current environment - the COVID-19 pandemic. Drawing from EST (Morgeson et al., 2015), we incorporate critical variables pertaining to the COVID-19 context and thus respond to calls for research that focuses on the context of anxiety (Morgeson \& Ryan, 2009), as well as the context of the applicant experience 
(McCarthy et al., 2017a). We focus on COVID-19 rumination and COVID-19 exhaustion as two individual experiences that are embedded in a high-stress, high-stakes situation (job interviews amid the pandemic) and shape applicants' interview anxiety as a reaction to this situation. This is important, as rumination and exhaustion have been identified as critical considerations with respect to the current pandemic (Bakker \& van Wingerden, in press; Caldas et al., 2021) and are salient to the study of anxiety (Kircanski et al., 2018; Koutsimani et al., 2019). Further, we focus on three factors related to the pandemic (i.e., COVID-19 duration, cases, and deaths) that capture components of EST, event time and event strength, and examine their effects on COVID-19 exhaustion.

Third, we focus our conceptual model on the experience of anxiety during a new but increasingly prevalent selection procedure, a virtual job interview. Our focus on virtual interviews is timely given that $86 \%$ of organizations have implemented them in some form since the onset of COVID-19 (Bayern, 2020), and many organizations plan to continue to use them in the future (McFarlane, 2021). For example, the use of asynchronous video interviews (AVIs; Maurer, 2020) has surged. In AVIs, job candidates respond to a series of technology-mediated interview questions, and their responses are recorded and later evaluated by either a hiring manager or by means of artificial intelligence (AI). However, empirical research on virtual interviews is "mostly unchartered territory" (Lukacik et al., in press, p. 11). As an attempt to fill this void, our study is the first to examine how interview anxiety relates to actual interview reactions and performance. Our focus on virtual interviews in a high-stakes selection setting enhances understanding of a selection tool that is increasingly used but not deeply understood or studied (Lukacik et al., in press).

\section{Theoretical Background and Hypothesis Development}

Theoretical models of job interview anxiety differentiate distinct types of anxiety (e.g., performance, social, appearance; McCarthy \& Goffin, 2004). Performance anxiety in this context is 
distress related to interview performance, and applicants often note great anxiety around this selection event (Lukacik et al., in press). This is consistent with theories of workplace anxiety, which focus on feelings of distress with respect to job-related performance (Calderwood et al., 2018; Cheng \& McCarthy, 2018). In alignment with this literature, we conceptualize job interview anxiety as feelings of nervousness and apprehension about one's interview performance. Thus, congruent with past theory and research, interview anxiety reflects a domain-specific construct (performance in the interview) and represents a response to stressors in the form of a strain symptom (Jex, 1998).

EST (Morgeson et al., 2015) posits that discrete events that vary in terms of time, strength, and space play an important role in organizational life. While the pandemic is an event that is enduring in terms of event time, threatening in terms of event strength, and pervasive in terms of event space, it has also been experienced differently around the globe regarding how long it has lasted and how disruptive it is, creating a salient and impactful context wherein the job interview occurs. Applicants' experience with this context has high relevance for the study of applicant anxiety and associated outcomes. Moreover, literatures on workplace anxiety (e.g., Bliese et al., 2017; Cheng \& McCarthy, 2018) and applicant reactions (e.g., Hausknecht et al., 2004; McCarthy et al., 2017a) highlight the role played by person and environment factors in the experience of anxiety. However, despite calls for research, empirical studies have tended to focus solely on the role of environmental conditions such as the type of test applicants take, or solely on individual differences such as personality (McCarthy et al., 2017a). Our focus on COVID-19 rumination moves beyond past models, as it reflects repetitive cognitions experienced by applicants (a person-based factor; Baranik et al., 2017; Nolen-Hoeksema et al., 2008) that occur with respect to the current pandemic (an environment-based factor). Similarly, COVID-19 exhaustion reflects feelings of mental depletion (a person-based factor; Maslach et al., 2001) that occur with respect to the pandemic (an 
environment-based factor). Rumination and exhaustion are central to understanding applicant anxiety in general as well as in the midst of COVID-19, as each has been associated with reductions in overall physical and mental well-being since the onset of the current pandemic (e.g., Bakker \& van Wingerden, in press; Barello et al., 2020; Meseguer de Pedro et al., 2021). As outlined below, each is likely to play a critical role in levels of interview anxiety among applicants faced with the challenge of virtual job interviews. Thus, our examination of individual experiences situated within the context of the pandemic - COVID-19 rumination and COVID-19 exhaustion - aligns with existing literature and represents a significant extension of past work.

Rumination is one of the driving forces of anxiety (Watkins, 2008). This occurs because continuous repetitive thoughts about threatening events have been found to interfere with the ability to focus on current tasks and solve problems effectively (Nolen-Hoeksema et al., 2008), which may trigger feelings of anxiety about the capacity to perform well. Applied to the current context, this means that applicants who are unable to take their mind off the threat of COVID-19 during the interview are more likely to feel nervous about not performing well. Although research has yet to examine this in the context of job interviews, there is work demonstrating that rumination predicts levels of general anxiety (Calmes \& Roberts, 2007), clinical anxiety (Nolen-Hoeksema, 2000), and test-related anxiety (Krys et al., 2020). In further alignment with our theoretical framework, rumination that specifically pertains to a significant environmental event can serve as an antecedent of anxiety. Our focus on COVID-19 rumination is an example of such as a relationship: Applicants may find themselves unable to stop thinking about the threat (Demsky et al., 2019; Martin \& Tesser, 1996) ${ }^{1}$ and may experience pandemic-related rumination during the interview, which in turn may be associated with higher job interview anxiety.

Hypothesis 1: COVID-19 rumination is associated with interview anxiety. 
We further predict that this relation between COVID-19 rumination and the experience of interview anxiety will be exacerbated to the extent that applicants are also experiencing emotional exhaustion. Emotional exhaustion is a state of mental depletion resulting from demanding experiences (Halbesleben \& Bowler, 2007; Liu et al., 2015). In our research context, a high level of COVID-19 exhaustion may indicate that COVID-19 (and its associated resource threat and loss) has resulted in a substantial depletion in job applicants' regulatory resources prior to or during the virtual job interviews (Hobfoll, 1991). Thus, when job applicants are unable to stop thinking about COVID19 and at the same time are experiencing emotional exhaustion as a result of COVID-19, their resources are likely to be depleted and their ability to focus on the interview is further compromised, resulting in higher levels of interview anxiety. On the other hand, low levels of COVID-19 exhaustion are associated with higher levels of regulatory resources for the job applicant, such that COVID-19 rumination will have a weaker influence on interview anxiety.

Hypothesis 2: COVID-19 exhaustion will interact with COVID-19 rumination to affect interview anxiety, such that rumination's effects on anxiety will be stronger under conditions of high COVID-19 exhaustion and weaker under conditions of low COVID-19 exhaustion.

In the second part of our model, we propose that interview anxiety will be negatively related to three critical outcomes for applicants and organizations - job applicant interview performance, fairness perceptions, and recommendation intentions. A number of studies have examined the effect of interview anxiety on interview performance, and a recent meta-analysis found a significant negative association between the two (Powell et al., 2018). Yet, critically, there have been no studies that examine this relationship in a field setting with actual job applicants. Instead, nearly all studies have used mock interviews with student populations ${ }^{2}$, leading to calls for research that assesses interview anxiety in real, high-stakes field settings (Powell et al., 2018). Relevant to our study, the relationship between anxiety and interview performance has also not been examined in actual virtual 
interviews, nor has it been examined under such stressful circumstances as a global pandemic.

Nevertheless, these earlier studies are informative because they suggest that interview anxiety has a negative relation with interview performance. This is not surprising, as anxiety affects thoughts and behaviors. With respect to thoughts, theories of interview anxiety (McCarthy \& Cheng, 2018) and general theories of anxiety (Cheng \& McCarthy, 2018; Eysenck et al., 2007) indicate that anxiety directs attention away from the task at hand such that individuals may have difficulty performing well. With respect to behaviors, applicants with high interview anxiety are less likely to engage in impression management (Budnick et al., 2019) and more likely to engage in deleterious non-verbal behaviors, such as averted eye contact and shaky speech (DeGroot \& Gooty, 2009; Feiler \& Powell, 2016), which in turn affect applicant performance in the interview (Barrick et al., 2009).

Hypothesis 3: Interview anxiety is associated with lower performance in virtual job interviews.

It is also critical to consider the effects of interview anxiety on key issues for organizations, such as applicants' fairness perceptions and recommendation intentions. Fairness perceptions reflect the extent to which applicants view the selection process as fair (Bauer et al., 2001), while recommendation intentions, known as Net Promoter Scores in the corporate realm (Reichheld, 2003), assess the extent to which individuals will recommend the organization to others. Both constructs have been extensively used by firms (Martin, 2020; Puskoor, 2020) to assess the extent to which employees, applicants, and customers perceive an organization as an attractive place to work or do business.

Literatures on applicant reactions hold that when applicant anxiety is high, fairness perceptions and recommendation intentions will be low (Hausknecht et al., 2004; McCarthy et al., 2017a). In part, this is because anxiety occurs when individuals are threatened and fear losing valuable resources - in the current situation, when a job is not acquired (Lazarus \& Lazarus, 1994). 
Specifically, anxiety causes them to be on high alert and directs their focus to the source of the threat (Bar-Haim et al., 2007). As a result of this anxious state, individuals pay close attention to the details of the job interview and become particularly sensitive to the potential threats (e.g., unfair treatment) during the process (Schmitt \& Dörfel, 1999). Anxiety may also trigger a psychological defense process to protect self-esteem and maintain a positive self-view (Allport, 1954; Kouchaki \& Desai, 2015). We argue that when an applicant feels anxious about not performing well in the interview, they engage in ego protection by justifying that the interview is unfair. In line with our reasoning, research shows that general levels of anxiety are negatively related to perceptions of justice (Bondü \& Inerle, 2020; Lind \& Van den Bos, 2002) and computer-related anxiety is negatively related to fairness perceptions in a simulated selection paradigm (Wiechmann \& Ryan, 2003).

Turning to recommendation intentions, anxiety is also associated with avoidance-oriented behavior (Dymond \& Roche, 2009) as a way to avoid or escape from negative stimuli (Bauer \& Spector, 2015). In the case of job interviews, this means that anxious applicants are more likely to want to avoid the organization to which they are applying - thus their recommendation intentions are likely to be low. In line with this, research has found that applicant test anxiety is positively related to withdrawal from a selection process (Schmitt \& Ryan, 1997) and negatively related with attitudes towards the organization (Van Esch et al., 2019).

Applied to the current context, interview anxiety is expected to relate to the perceived fairness of the interview and recommendation intentions. To our knowledge, only two studies have investigated the relationship between interview anxiety and fairness perceptions. While neither found significant results, neither considered virtual interviews or the broader environmental context (Banki \& Latham, 2010; Melchers et al., 2020). Further, no studies have examined the relation between applicant anxiety and recommendation intentions, let alone in virtual interview settings. 
Hypothesis 4: Interview anxiety is associated with (a) lower fairness perceptions and (b) lower recommendation intentions.

In sum, Hypotheses 1-4 suggest that COVID-19 exhaustion moderates the relation between COVID-19 rumination and interview anxiety, and that in turn, interview anxiety is related to interview performance, fairness perceptions, and recommendation intentions. Thus, we posit:

Hypothesis 5: COVID-19 exhaustion will moderate the indirect relation between COVID-19 rumination and interview performance, such that the indirect effect is stronger (versus weaker) when COVID-19 exhaustion is higher (versus when it is lower).

Hypothesis 6: COVID-19 exhaustion will moderate the indirect relation between COVID-19 rumination and (a) perceived fairness, such that the indirect effect is stronger (versus weaker) when COVID-19 exhaustion is higher (versus when it is lower); and (b) recommendation intentions, such that the indirect effect is stronger (versus weaker) when COVID-19 exhaustion is higher (versus when it is lower).

\section{The Role of COVID-19 Event Duration and Strength}

In line with EST, the COVID-19 pandemic is seen as a high-duration and strong event. By embedding our work directly within COVID-19, we address the need to examine applicant reactions under broad, system-level conditions (McCarthy et al., 2017a). The only such meta-level factor that has received much scrutiny in the applicant reaction literature is applicant country (e.g., Anderson et al., 2010). This is unfortunate, because as highlighted in theories of stress (e.g., Bakker \& Demerouti, 2007; Hobfoll, 1989; Maslach et al., 2001), traumatic environmental events can have an impact on emotional exhaustion via resource depletion. Traumatic environmental events are those that happen unexpectedly, make excessive demands, and threaten resources (e.g., wars, terrorist attacks, natural disasters; see Hobfoll, 1991; Hobfoll et al., 1995; Vinokur, et al., 2011). The COVID-19 pandemic is a vivid example of a traumatic event that has threatened individual resources by increasing feelings of uncertainty and loss regarding illness and death, job security, social connections, and much more (Kniffin et al., 2020). The threat and loss associated with these resources is likely to have a direct impact on the extent to which individuals experience 
emotional exhaustion, because by its very nature, emotional exhaustion reflects a state wherein individuals feel drained, depleted, and fatigued by excessive demands on resources (Halbesleben et al., 2013; Hobfoll \& Freedy, 1993). Empirical research supports these arguments, as extreme environmental events, such as war and job furloughs, have been found to have a direct impact on the experience of emotional exhaustion (see Halbesleben et al., 2013; Vinokur et al., 2011). Evidence suggests that aspects of the COVID-19 pandemic are increasing emotional exhaustion among working employees (Caldas et al., 2021; Lin et al., 2021; Moreno-Jiménez et al., 2021). Although the COVID-19 pandemic is a shared event for everyone during this difficult time, the extent to which this pandemic exerts demands on one's resources and results in COVID19 exhaustion may vary. According to EST (Morgeson et al., 2015), an event's impact depends on event time (when an event occurs and how long it lasts), event strength (the extent to which an event is salient and commands attention), and event space (where an event originates). In this study, we focus on event strength and event time, as there is little variance with respect to event space - COVID-19 exists at the environment level and has become a global phenomenon. When an event lasts longer and features higher salience, it requires individuals to allocate more resources, attention, and effort to respond to it (Morgeson et al., 2015), thereby resulting in higher levels of exhaustion. Applying the rationales of EST to the current research context, we focus on COVID-19 duration (i.e., the cumulative number of days by the time of interview since the outbreak was declared by WHO) to capture event time, as well as COVID-19 cases (i.e., the cumulative number of cases in the applicant's location) and COVID-19 deaths (i.e., the cumulative number of deaths in the applicant's location) by the time of interview to capture event strength. Based on EST, we argue that applicants for whom COVID-19 is enduring longer and more threatening (i.e., more COVID-19 cases and deaths in the surroundings) may have consumed a 
larger amount of resources to respond to and deal with COVID-19, rendering higher levels of

COVID-19 exhaustion at the time of interview. Hence, we propose that each of these event-based factors will be positively related to COVID-19 exhaustion.

Hypothesis 7: (a) COVID-19 duration, (i.e., cumulative number of days since outbreak), (b) COVID-19 cases, (i.e., cumulative \# of cases by location) and (c) COVID-19 deaths (i.e., cumulative \# of deaths by location), will be positively associated with COVID-19 exhaustion.

\section{Method}

\section{Participants and Procedure}

We collected data from job applicants who took a virtual interview with their prospective employers on a platform provided by a US-based recruiting technology company. Job applicants were given a survey invitation at the end of their interview, which was administered between April 29 to August 3, 2020. We assured applicants that their survey responses would be kept confidential and used for research purposes only and that their survey responses would have no impact on their job application results. Survey invitations were given to a total of 736,559 applicants undergoing a virtual interview (specifically, an AVI) on the platform. Of those, 9,619 applicants interviewing with 395 organizations agreed to participate and were directed to the survey. In the end, 8,343 applicants (response rate $=1.1 \%)^{3}$ interviewing for 373 organizations in 73 countries (ranging from Albania to Zimbabwe) completed the survey. Of the 8,343 participants, $74 \%$ completed the interview in the US or Canada, and $43 \%$ indicated that they were employed at the time of the interview. According to a demographic prediction algorithm (please see Appendix A for details), participants' average (predicted) age was 37.23 years $(S D=12.46)$, and $52 \%$ of them were (predicted) female. Participants completed surveys measuring COVID-19 rumination, COVID-19 exhaustion, interview anxiety, perceived fairness, and recommendation intentions. The recruiting technology company provided data on interview performance with the job applicants' and employers' consent. 


\section{Measures}

Unless otherwise noted, participants rated the extent to which they agreed with each item on a 5 -point Likert scale $(1=$ strongly disagree to $5=$ strongly agree $)$. Items are presented in Appendix B. In alignment with general measures of rumination (McCullough et al., 2007), COVID-19 rumination was assessed with three items $(\alpha=.79)$ adapted from a measure of job applicant off-task processing (McCarthy et al., 2009). COVID-19 exhaustion was measured with four items $(\alpha=.89)$ adapted from Wharton (1993) to reflect applicants' exhaustion as a result of COVID-19. Interview anxiety was assessed with the six-item $(\alpha=.89)$ performance anxiety subscale from McCarthy and Goffin (2004). Interview performance was a percentile score standardized within each organization by an automated scoring algorithm, indicating how well the applicant performed in the virtual interview compared to other candidates applying for the same kind of jobs in the organization. Scores ranged from 0 to 1 (higher value = better performance). Scores were based on two factors: organization-specific machine learning algorithms where applicants' interview responses were used to predict key criterion measures, and non-organizationspecific machine learning algorithms built to predict ratings of key competencies as demonstrated in the interview. ${ }^{4}$ Perceived fairness was assessed with two items (Spearman-Brown $=.79$ ) from Bauer et al.’s (2001) SPJS. ${ }^{5}$ Recommendation intentions were assessed using (Reichheld, 2003) $(0=$ not at all likely, $10=$ extremely likely): "Based on the experience you just had, how likely are you to recommend [employer's name] to a friend or colleague?"

In order to examine aspects of EST and our associated hypotheses, we focused on Canada and the United States $(n=6,136)$ rather than the full sample as we did not have data available on the state or province where participants in other countries completed their interview. COVID-19 duration was assessed by computing the number of days since the COVID-19 outbreak was 
declared as a pandemic by the WHO (March 11,2020) relative to each applicant's interview date. COVID-19 cases (number of COVID-19 cases) and COVID-19 deaths (number of COVID-19 deaths) were assessed for the 50 states and District of Columbia in the United States as well as the 10 provinces and 3 territories in Canada on each day during the timespan of virtual job interviews in our dataset (April 29, 2020 to August 3, 2020). The United States' state-level data were obtained from an ongoing open-access data repository released by the New York Times (https://github.com/NYtimes/covid-19-data), and the Canadian province-level data were obtained from Berry et al. (2020; https://github.com/ccodwg/Covid19Canada). We also obtained the state/province-level population data in both countries (Statistics Canada, 2021 and United States Department of Agriculture Economic Research Service, 2020 respectively). The cumulative cases and deaths (per 1,000 people) were computed by dividing the cumulative number of cases and deaths by the state/province population and multiplying by 1,000 .

Control variables. We included several applicant (predicted age, predicted gender, predicted race, location, employment status, telework status, and managerial status) and employer (employer size and industry sector) characteristics as control variables as they may impact interview anxiety and interview performance (e.g., Powell et al., 2018). We also controlled for the date of the interview due to the dynamic nature of the pandemic. Please see Appendix A for additional details.

\section{Results}

Table 1 presents means, standard deviations, reliabilities, and intercorrelations among study variables. In light of the nested data structure (job applicants nested in employers), we followed prior research (e.g., Liu et al., 2015) and used the sandwich estimator in conducting analyses with Mplus 8.1 (Muthén \& Muthén, 1998-2017) to control for organization-based clustering. ${ }^{6}$ The missing values in variables were modeled using full-information maximum likelihood estimator. 
We first conducted a CFA to examine whether our measures captured distinct constructs, and findings supported our proposed model. ${ }^{7}$ We then conducted path modeling analyses to test our hypotheses. Predictors were mean-centered before creating the interaction term or being entered into the model. Unstandardized path model results are presented in Table 2 and illustrated in Figure $2 .{ }^{8}$ Our findings remain the same regardless of whether our control variables are included or not.

We found that COVID-19 rumination was positively related to interview anxiety $(\gamma=.10, p<$ $.001)$, and COVID-19 exhaustion moderated this relationship $(\gamma=.03, p=.004)$. The interaction pattern is illustrated in Figure 4. Simple slope analyses revealed that the positive effect of COVID19 rumination on interview anxiety was stronger $(\gamma=.13, p<.001)$ when COVID-19 exhaustion was high (1 SD above the mean); this effect was weaker $(\gamma=.07, p=.01)$ when COVID-19 exhaustion was low (1 SD below the mean). These results supported Hypotheses 1 and 2 . Further, interview anxiety was negatively related to interview performance $(\gamma=-.03, p=.01),{ }^{9}$ perceived fairness $(\gamma=-$ $.23, p<.001)$, and recommendation intentions $(\gamma=-.20, p<.001)$, supporting Hypotheses 3 and 4 .

We tested the moderated mediation hypotheses (Hypotheses 5 \& 6) using the 20,000repetition Monte Carlo procedure in $R$ (Preacher et al., 2010; see Table 3). The indirect effect of COVID-19 rumination on interview performance via interview anxiety was stronger (95\% CI [-.007, -.001]) when COVID-19 exhaustion was high (+1 SD), and was weaker (95\% CI [-.005, -.0002]) when COVID-19 exhaustion was low (-1 SD). The difference between these two conditional indirect effects was significant, as the 95\% CI ([-.004, -.0004]) did not contain zero. Thus, Hypothesis 5 was supported. Similarly, the indirect effect of COVID-19 rumination on perceived fairness was stronger (95\% CI [-.038, -.025]) when COVID-19 exhaustion was high, and was weaker (95\% CI [-.025, .004]) when COVID-19 exhaustion was low. The difference between these two conditional indirect effects was significant (95\% CI [-.027, -.005]). The indirect effect of COVID-19 rumination on 
recommendation intentions was stronger (95\% CI [-.034, -.019]) when COVID-19 exhaustion was high and was weaker (95\% CI [-.022, -.004]) when COVID-19 exhaustion was low. The difference between these two conditional indirect effects was significant (95\% CI [-.024, -.004]). Hence, Hypotheses $6 \mathrm{a}$ and $6 \mathrm{~b}$ were supported.

Hypothesis 7 was tested with our Canadian and US job applicants (74\% of sample, $n=$ 6,136). We estimated a path model that included effects of COVID-19 duration, COVID-19 cases, and COVID-19 deaths on COVID-19 exhaustion (see Figure 3). Control variables were consistent with the previous analyses. Figure 3 illustrates the unstandardized path model results. Consistent with Hypotheses 7a and 7c, COVID-19 duration $(\gamma=.002, p=.01)$ and COVID-19 deaths $(\gamma=.20, p$ $=.004)$ were positively related to COVID-19 exhaustion. Further, the analysis of our subsample replicated our findings for the model tested with all respondents. However, COVID-19 cases were not related to COVID-19 exhaustion $(\gamma=-.01, p>.05)$, thus Hypothesis $7 \mathrm{~b}$ was not supported.

\section{Discussion}

We advance and test a model of interview anxiety in a high-stress, high-stakes context during COVID-19. Our study is the first to examine the applicant experience of virtual interviews in a field setting and is one of the first to illustrate the relationship between anxiety and interview performance in an actual hiring situation. Consistent with predictions, COVID-19 duration and COVID-19 deaths were directly related to applicants' COVID-19 exhaustion. High levels of COVID-19 exhaustion, in turn, exacerbated the relationship between COVID-19 rumination and interview anxiety.

Subsequently, interview anxiety was associated with less favorable applicant perceptions and lower interview performance.

\section{Theoretical and Practical Implications}

We draw from EST (Morgeson et al., 2015) to advance and test a conceptual model of 
applicant reactions to AVIs that is embedded in the COVID-19 context. Specifically, our model extends literatures on workplace anxiety and applicant reactions by answering calls for research examining broad, system-level conditions (Morgeson et al., 2015). Although past research has focused on understanding outcomes of test and interview anxiety (e.g., Schneider et al., 2019), less is known about context/event-specific experiences that predispose applicants to feel anxious during the job interview. Our work indicates that context plays a critical role and demonstrates that the experience of interview anxiety involves a complex interplay between environment-based factors (COVID-19 duration and deaths) and personal experience with the context (COVID-19 rumination and exhaustion). Our finding that event duration matters is particularly important given the continued global uncertainty with respect to when this pandemic will end (WHO, 2021), as well as recent suggestions that pandemics may be the new normal for our future (Phillips, 2021). The effects with respect to COVID-19 deaths are also notable, as death counts have varied widely across countries/regions around the globe and have been found to be influenced by a variety of factors, including timing of lockdowns, vaccine rollouts, and regional wealth (Wouters et al., 2021). Thus, applicants living in countries and regions that have been hardest hit in terms of death counts have a double-whammy, as they are also those most likely to experience COVID-19 exhaustion. In turn, this may impact job prospects via its effect on interview anxiety. Our findings also help advance EST because existing empirical work on EST has mainly focused on event strength (Lin et al., 2021; Liu et al., 2021). By empirically demonstrating the importance of event duration, we expand the research on event time and advance the testing of EST.

It is also notable that past work in the field of applicant reactions has focused heavily on perceptions of justice, drawing from Gilliland's $(1993,1994)$ theoretical work highlighting the role of applicants' fairness perceptions on subsequent behaviors, attitudes, and intentions. Our 
work moves beyond this framework and enhances our understanding of applicant anxiety as it applies to interviews in general, and virtual interviews specifically. We found that the levels of interview anxiety related to outcomes that applicants and organizations value highly - interview performance (a behavior), fairness perceptions (an attitude), and recommendation intentions (an intention). This suggests that in addition to fairness perceptions, anxiety is an important consideration with respect to research on job applicants. Further, our focus on a high-stakes context (interviews for actual employment) rendered the magnitude of interview anxiety higher than in past work (which has focused primarily on simulated interviews and has not been conducted in the midst of a crisis). ${ }^{10}$ Taken together, these findings highlight that applicant anxiety is something that organizations may want to pay attention to and aim to reduce, particularly during times of societal upheaval when anxiety levels may be high.

There are practical implications of our work for both job applicants and organizations. From the applicant's perspective, the COVID-19 pandemic has created a paradox because it is linked to increases in both job search behavior (McFarland et al., 2020) and COVID-19 exhaustion (as found in our study). As a result, applicants may suffer from a double-bind of needing to perform well in job interviews at a time when it is the most challenging for them to do so. This is compounded by the fact that many applicants are not yet familiar with AVI formats, which can increase the uncertainty with respect to the interview process. However, virtual interviews are becoming more and more prevalent, as the speed and consistency with which such applied AI can help hire quickly is desirable to organizations (Campion et al., 2016). Thus, applicants would be well advised to practice techniques to minimize rumination, such as meditation (Jain et al., 2007), as well as avoiding activities that may lead to exhaustion, such as "doomscrolling".

We also note that the relationship between interview anxiety and performance observed in 
the current study was similar to past estimates that have focused on face-to-face interviews with actual applicants (Powell et al., 2018). This has implications for AVIs because as they become less novel they may become less anxiety-provoking. Lower levels of anxiety, in turn, are likely to lead to improvements in AVI performance. Future research is needed to examine this proposition, as well as to understand key features related to interview anxiety and different types of interviews-

Finally, our work has implications for future societal shocks. For example, natural disasters, political unrest, economic downturns, and/or future pandemics could lead to situations where those with the greatest need for employment might be the most likely to ruminate and experience exhaustion and anxiety which, in turn, affects their ability to perform when it comes to securing employment. Gaining an understanding of these processes during the current crisis is important. Based on our study, lowering applicants' anxiety and strengthening their focus during the interview seems important for helping applicants perform well and for helping organizations meet their staffing needs, avoid missing good hires, and safeguard their reputations.

\section{Potential Limitations}

Regarding our research methods, a number of design aspects are potential limitations. For example, due to the cross-sectional design used to test many relationships, the causal ordering of our model is not the only one possible. For example, anxiety may be driving COVID-rumination or exhaustion rather than the other way around. However, while the causal ordering of our moderated relationships cannot rule out alternative ordering, our post hoc analyses did not support models in which interview anxiety impacted outcomes through rumination or exhaustion. Future studies using longitudinal designs would help extend our cross-sectional research and allow for an examination of applicant anxiety over time. Of particular value would be research that considers how anxiety unfolds throughout the recruitment process, such as in anticipation of the interview, during the 
interview, and after the interview but before receiving a decision.

Our study was multi-source (job applicant surveys; AI-rated interview scores; pandemic data in different geographic areas) and examined moderation, which is less susceptible to common method concerns. Further, although our sample size was large, our response rate was modest, and our results should thus be interpreted with appropriate caution. Further, although our measure of recommendation intentions was consistent with its intended organizational use (Reichheld, 2003), it was a single-item measure. This concern may be mitigated given that interview anxiety was also significantly related to our multi-item measure of fairness. Nevertheless, the findings regarding recommendation intentions should be interpreted with some caution. Finally, we note that our findings may also have been affected by applicant mood, and future results would benefit from integrating NA and other relevant personality traits into models of interview anxiety.

\section{Future Research Directions}

Our results highlight a number of valuable directions for future research. To begin, it would be advantageous for future work to take a more nuanced approach to the study of rumination by considering the precise source of intrusive thoughts. While our focus was on general levels of rumination with respect to the current pandemic, more nuanced measures could consider whether rumination is focused on concerns related to health, family, job security, and/or childcare. For example, specific types of rumination may be more or less related to the cognitive experience of interview anxiety. Moving beyond the current pandemic, it would be valuable for future work to consider the core features of other events that may play a role in the experience of AVI anxiety, such as cyber terrorism, economic recessions, and/or health issues. Finally, future research may examine whether the moderation effect of emotional exhaustion on relation between rumination and anxiety can generalize to periods of non-crisis, such as for employees faced with the challenge of new job responsibilities, new leadership and/or new team members. 
Our study also indicates that levels of interview anxiety have significant implications for outcomes that applicants and organizations value highly - interview performance, interview fairness, and recommendation intentions - and as such underscores the need for future research on techniques that alleviate applicant anxiety. We recommend brief, "wise interventions" (Walton, 2014), such as short explanations that can affect test-taker reactions (McCarthy et al., 2017b), for their practicality and likelihood of organizational adoption. For example, live interviewers could be trained to reassure applicants, and virtual interviews could include explanations that they are being used to protect applicants and/or choice over questions could be enabled (Salend, 2011).

\section{Conclusion}

The COVID-19 pandemic has had a significant impact on global levels of employment. As the first study to examine how virtual interview anxiety relates to interview performance, fairness perceptions, and recommendation intentions in an actual hiring setting, we extend the existing research on applicant reactions, rumination, and anxiety in a high-stress, high-stakes context where interview performance and employment are critical for job applicants. Our study provides insights of the applicant experience and its outcomes during a long-lasting and extremely severe event. 


\section{References}

Allport, G. W. (1954). The nature of prejudice. Addison-Wesley.

Anderson, N., Salgado, J. F., \& Hülsheger, U. R. (2010). Applicant reactions in selection:

Comprehensive meta - analysis into reaction generalization versus situational specificity. International Journal of Selection and Assessment, 18, 291-304.

Bakker, A. B., \& Demerouti, E. (2007). The job demands - resources model: State of the art. Journal of Managerial Psychology, 22, 309-328.

Bakker, A. B., \& van Wingerden, J. (in press). Do personal resources and strengths use increase work engagement? The effects of a training intervention. Journal of Occupational Health Psychology. Online First.

Banki, S., \& Latham, G. P. (2010). The criterion-related validities and perceived fairness of the situational interview and the situational judgment test in an Iranian organisation. Applied Psychology, 59, 124-142.

Baranik, L. E., Wang, M., Gong, Y., \& Shi, J. (2017). Customer mistreatment, employee health, and job performance: Cognitive rumination and social sharing as mediating mechanisms. Journal of Management, 43, 1261-1282.

Barrick, M. R., Shaffer, J. A., \& DeGrassi, S. W. (2009). What you see may not be what you get: relationships among self-presentation tactics and ratings of interview and job performance. Journal of Applied Psychology, 94, 1394-1411.

Bar-Haim, Y., Lamy, D., Pergamin, L., Bakermans-Kranenburg, M. J., \& Van Ijzendoorn, M. H. (2007). Threat-related attentional bias in anxious and nonanxious individuals: A meta-analytic study. Psychological Bulletin, 133, 1-24.

Barello, S., Palamenghi, L., \& Graffigna, G. (2020). Burnout and somatic symptoms among frontline healthcare professionals at the peak of the Italian COVID-19 pandemic. Psychiatry Research, 290, 113-129.

Basch, J. M., \& Melchers, K. G. (2019). Fair and flexible?! Explanations can improve applicant reactions toward asynchronous video interviews. Personnel Assessment and Decisions, 5, 1-11.

Bauer, J. A., \& Spector, P. E. (2015). Discrete negative emotions and counterproductive work behavior. Human Performance, 28, 307-331.

Bauer, T. N., Truxillo, D. M., Sanchez, R. J., Craig, J. M., Ferrara, P., \& Campion, M. A. (2001). Applicant reactions to selection: Development of the selection procedural justice scale (SPJS). 
Personnel Psychology, 54, 387-419.

Bayern, M. (2020). 86\% of companies are conducting job interviews via video conference.

TechRepublic. https://www.techrepublic.com/article/86-of-companies-are-conductingjobinterviews-via-video-conference/

Berry I., Soucy J-PR., Tuite A., \& Fisman D. (2020). Open access epidemiologic data and an interactive dashboard to monitor the COVID-19 outbreak in Canada. CMAJ, 14, 192.

Bliese, P. D., Edwards, J. R., \& Sonnentag, S. (2017). Stress and well-being at work: A century of empirical trends reflecting theoretical and societal influences. Journal of Applied Psychology, 102, 389-402.

Bondü, R., \& Inerle, S. (2020). Afraid of injustice? Justice sensitivity is linked to general anxiety and social phobia symptoms. Journal of Affective Disorders, 272, 198-206.

Budnick, C. J., Anderson, E. M., Santuzzi, A. M., Grippo, A. J., \& Matuszewich, L. (2019). Social anxiety and employment interviews: does nonverbal feedback differentially predict cortisol and performance? Anxiety, Stress, \& Coping, 32, 67-81.

Caldas, M. P., Ostermeier, K., \& Cooper, D. (2021). When helping hurts: COVID-19 critical incident involvement and resource depletion in health care workers. Journal of Applied Psychology, 106, 29-47.

Calderwood, C., Bennett, A. A., Gabriel, A. S., Trougakos, J. P., \& Dahling, J. J. (2018). Too anxious to help? Off-job affective rumination as a linking mechanism between work anxiety and helping. Journal of Occupational and Organizational Psychology, 91, 681-687.

Calmes, C. A., \& Roberts, J. E. (2007). Repetitive thought and emotional distress: Rumination and worry as prospective predictors of depressive and anxious symptomatology. Cognitive Therapy and Research, 31, 343-356.

Campion, M. C., Campion, M. A., Campion, E. D., \& Reider, M. H. (2016). Initial investigation into computer scoring of candidate essays for personnel selection. Journal of Applied Psychology, 101, 958-975.

CareerBuilder (2017). Exclusive insights from 207 candidate experience study. https://resources.careerbuilder.com/guides/candidate-experience-guide

Chapman, D. S., Uggerslev, K. L., Carroll, S. A., Piasentin, K. A., \& Jones, D. A. (2005). Applicant attraction to organizations and job choice: A meta-analytic review of the correlates of recruiting outcomes. Journal of Applied Psychology, 90, 928-944. 
Cheng, B. H., \& McCarthy, J. M. (2018). Understanding the dark and bright sides of anxiety: A theory of workplace anxiety. Journal of Applied Psychology, 103, 537-560.

DeGroot, T., \& Gooty, J. (2009). Can nonverbal cues be used to make meaningful personality attributions in employment interviews? Journal of Business and Psychology, 24, 179-192.

Demsky, C. A., Fritz, C., Hammer, L. B., \& Black, A. E. (2019). Workplace incivility and employee sleep: The role of rumination and recovery experiences. Journal of Occupational Health Psychology, 24, 228-240.

Dymond, S., \& Roche, B. (2009). A contemporary behavior analysis of anxiety and avoidance. The Behavior Analyst, 32, 7-27.

Eurostat (2020). COVID-19 labour effects across the income distribution. Downloaded on January 15, 2021 from https://ec.europa.eu/eurostat/web/products-eurostat-news/-/DDN-20201027-2

Eysenck, M. W., Derakshan, N., Santos, R., \& Calvo, M. G. (2007). Anxiety and cognitive performance: attentional control theory. Emotion, 7, 336-353.

Feiler, A. R., \& Powell, D. M. (2016). Behavioral expression of job interview anxiety. Journal of Business and Psychology, 31, 155-171.

Gilliland, S. W. (1993). The perceived fairness of selection systems: An organizational justice perspective. Academy of Management Review, 18, 694-734.

Gilliland, S. W. (1994). Effects of procedural and distributive justice on reactions to a selection system. Journal of Applied Psychology, 79, 691-701.

Halbesleben, J. R., \& Bowler, W. M. (2007). Emotional exhaustion and job performance: The mediating role of motivation. Journal of Applied Psychology, 92, 93-106.

Halbesleben, J. R., Leroy, H., Dierynck, B., Simons, T., Savage, G. T., McCaughey, D., \& Leon, M. R. (2013). Living up to safety values in health care: The effect of leader behavioral integrity on occupational safety. Journal of Occupational Health Psychology, 18, 395-405.

Hausknecht, J. P., Day, D. V., \& Thomas, S. C. (2004). Applicant reactions to selection procedures: An updated model and meta-analysis. Personnel Psychology, 57, 639-683.

Hobfoll, S. E. (1989). Conservation of resources: a new attempt at conceptualizing stress. American psychologist, 44, 513-524.

Hobfoll, S. E. (1991). Traumatic stress: A theory based on rapid loss of resources. Anxiety Research, 4, 187-197.

Hobfoll, S. E., Dunahoo, C. A., \& Monnier, J. (1995). Conservation of resources and traumatic stress. In 
J. R. Freedy, \& S. E. Hobfoll (Eds.), Traumatic stress: From theory to practice (pp. 29-47). Plenum Press, New York, NY.

Hobfoll, S. E., \& Freedy, J. (1993). Conservation of resources: A general stress theory applied to burnout. In WB Schaufeli, C. Maslach, \& T. Marek.(Eds.), Professional burn-out: Recent developmens in theory and research. (pp. 115-122). Taylor and Francis, London.

Jain, S., Shapiro, S. L., Swanick, S., Roesch, S. C., Mills, P. J., Bell, I., \& Schwartz, G. E. (2007). A randomized controlled trial of mindfulness meditation versus relaxation training: effects on distress, positive states of mind, rumination, and distraction. Annals of Behavioral Medicine, 33, 11-21.

Jex, S. M. (1998). Stress and job performance: Theory, research, and implications for managerial practice. Sage Publications Ltd.

Keenan, A. (1978). The selection interview: Candidates' reactions and interviewers' judgements. British Journal of Social and Clinical Psychology, 17, 201-209.

Kircanski, K., Thompson, R. J., Sorenson, J., Sherdell, L., \& Gotlib, I. H. (2018). The everyday dynamics of rumination and worry: Precipitant events and affective consequences. Cognition and Emotion, 32, 1424-1436.

Kniffin, K. M., Narayanan, J., Anseel, F., Antonakis, J., Ashford, S. P., Bakker, A. B., ... \& Vugt, M. V. (2020). COVID-19 and the workplace: Implications, issues, and insights for future research and action. American Psychologist, 76, 63-77.

Kouchaki, M., \& Desai, S. D. (2015). Anxious, threatened, and also unethical: How anxiety makes individuals feel threatened and commit unethical acts. Journal of Applied Psychology, 100, 360375.

Koutsimani, P., Montgomery, A., \& Georganta, K. (2019). The relationship between burnout, depression, and anxiety: A systematic review and meta-analysis. Frontiers in Psychology, 10, 284.

Krys, S., Otte, K. P., \& Knipfer, K. (2020). Academic performance: A longitudinal study on the role of goal-directed rumination and psychological distress. Anxiety, Stress, \& Coping, 33, 545-559.

Lazarus, R. S., \& Lazarus, B. N. (1994). Passion and reason: Making sense of our emotions. Oxford University Press, USA.

Lin, W., Shao, Y., Li, G., Guo, Y., \& Zhan, X. (2021). The psychological implications of COVID-19 on employee job insecurity and its consequences: The mitigating role of organization adaptive practices. Journal of Applied Psychology, 106, 317-329.

Lind, E. A., \& Van den Bos, K. (2002). When fairness works: Toward a general theory of uncertainty 
management. Research in Organizational Behavior, 24, 181-223.

Liu, D., Chen, Y., \& Li, N. (2021). Tackling the negative impact of COVID-19 on work engagement and taking charge: A multi-study investigation of frontline health workers. Journal of Applied Psychology, 106, 185-198.

Liu, Y., Wang, M., Chang, C.-H., Shi, J., \& Zhou, L. (2015). Work-family conflict, emotional exhaustion, and displaced aggression toward others: The moderating roles of workplace interpersonal conflict and perceived managerial family support. Journal of Applied Psychology, 100, 793-808.

Lukacik, E. R., Bourdage, J. S., \& Roulin, N. (in press). Into the void: A conceptual model and research agenda for the design and use of asynchronous video interviews. Human Resource Management Review, Advance online publication. https://doi.org/10.1016/ j.hrmr.2020.100789

Martin, N. (2020). Why candidate Net Promoter Scores (NPS) really matter. https://insights.humancapital.aon.com/talent-assessment-blog/why-nps-scores-really-matter Martin, L. L., \& Tesser, A. (1996). Some ruminative thoughts. Advances in Social Cognition, 9, 1-47. Maslach, C., Schaufeli, W. B., \& Leiter, M. P. (2001). Job burnout. Annual Review of Psychology, $52,397-422$.

Maurer, R. (2020). Job interviews go virtual in response to COVID-19. SHRM.

Maurer, R. (2021). First-time unemployment claims reach 900K. SHRM.

McCarthy, J. M., Bauer, T. N., Truxillo, D. M., Anderson, N. R., Costa, A. C., \& Ahmed, S. M. (2017a). Applicant perspectives during selection: A review addressing "So what?," "What's new?," and "Where to next?" Journal of Management, 43, 1693-1725.

McCarthy, J. M., Bauer, T. N., Truxillo, D. M., Campion, M. C., Van Iddekinge, C. H., \& Campion, M. A. (2017b). Using pre-test explanations to improve test-taker reactions: Testing a set of "wise" interventions. Organizational Behavior and Human Decision Processes, 141, 43-56.

McCarthy, J. M., \& Cheng, B. H. (2018). Through the looking glass: Employment interviews from the lens of job candidates. The Oxford Handbook of Job Loss and Job Search, 329-357.

McCarthy, J., \& Goffin, R. (2004). Measuring job interview anxiety: Beyond weak knees and sweaty palms. Personnel Psychology, 57, 607-637.

McCarthy, J., Hrabluik, C., \& Jelley, R. B. (2009). Progression through the ranks: Assessing employee reactions to high-stakes employment testing. Personnel Psychology, 62, 793-832.

McCullough, M. E., Bono, G., \& Root, L. M. (2007). Rumination, emotion, and forgiveness: Three 
longitudinal studies. Journal of Personality and Social Psychology, 92, 490-505.

McFarland, L. A., Reeves, S., Porr, W. B., \& Ployhart, R. E. (2020). Impact of the COVID-19

pandemic on job search behavior: An event transition perspective. Journal of Applied Psychology, 105, 1207-1217.

McFarlane, F. (2021, January). Preparing for the "New Normal": A guide to virtual interviews in 2021. The Web Writer Spotlight. https://webwriterspotlight.com/preparing-for-new-normalguide-to-virtual-interviews.

Melchers, K. G., Petrig, A., Basch, J. M., \& Sauer, J. (2020). A comparison of conventional and technology-mediated selection interviews with regard to interviewees' performance, perceptions, strain, and anxiety. Frontiers in Psychology, 11, 3851.

Meseguer de Pedro, M., Fernández-Valera, M. M., García-Izquierdo, M., \& Soler-Sánchez, M. I. (2021). Burnout, Psychological Capital and Health during COVID-19 Social Isolation: A Longitudinal Analysis. International Journal of Environmental Research and Public Health, 18, 1064-1075.

Moreno-Jiménez, J. E., Blanco-Donoso, L. M., Chico-Fernández, M., Belda Hofheinz, S., MorenoJiménez, B., \& Garrosa, E. (2021). The job demands and resources related to COVID-19 in predicting emotional exhaustion and secondary traumatic stress among health professionals in Spain. Frontiers in Psychology, 12, 1-12.

Morgeson, F. P., Mitchell, T. R., \& Liu, D. (2015). Event system theory: An event-oriented approach to the organizational sciences. Academy of Management Review, 40, 515-537.

Morgeson, F. P., \& Ryan, A. M. (2009). Reacting to applicant perspectives research: What's next? International Journal of Selection and Assessment, 17, 431-437.

Muthén, L. K., \& Muthén, B. O. (1998-2017). Mplus. Statistical analysis with latent variables. User's Guide.

Nolen-Hoeksema, S. (2000). The role of rumination in depressive disorders and mixed anxiety/depressive symptoms. Journal of Abnormal Psychology, 109, 504-511.

Nolen-Hoeksema, S., Wisco, B. E., \& Lyubomirsky, S. (2008). Rethinking rumination. Perspectives on Psychological Science, 3, 400-424.

Phillips, N. (2021). The coronavirus is here to stay-here's what that means. Nature, 590, 382-384.

Powell, D. M., Stanley, D. J., \& Brown, K. N. (2018). Meta-analysis of the relation between interview anxiety and interview performance. Canadian Journal of Behavioural Science, 50, 
195-207.

Preacher, K. J., Zyphur, M. J., \& Zhang, Z. (2010). A general multilevel SEM framework for assessing multilevel mediation. Psychological Methods, 15, 209-233.

Puskoor, D. (2020). What is a startup's first success story? Forbes, December.

Reichheld, F. F. (2003). The one number you need to grow. Harvard Business Review, 81, 46-55.

Salend, S. J. (2011). Addressing test anxiety. Council for Exceptional Children, 44, 58-68.

Schmitt, M., \& Dörfel, M. (1999). Procedural injustice at work, justice sensitivity, job satisfaction and psychosomatic well-being. European Journal of Social Psychology, 29, 443-453.

Schmitt, M. J., \& Ryan, A. M. (1997). Applicant withdrawal: The role of test-taking attitudes and racial differences. Personnel Psychology, 50, 855-876.

Schneider, L., Powell, D. M., \& Bonaccio, S. (2019). Does interview anxiety predict job performance and does it influence the predictive validity of interviews? International Journal of Selection and Assessment, 27, 328-336.

Statistics Canada (2021). https://www150.statcan.gc.ca/t1/tbl1/en/tv.action?pid=1710000901

Stumpf, S. A., Brief, A. P., \& Hartman, K. (1987). Self-efficacy expectations and coping with career-related events. Journal of Vocational Behavior, 31, 91-108.

Truxillo, D. M., Bodner, T. E., Bertolino, M., Bauer, T. N., \& Yonce, C. A. (2009). Effects of explanations on applicant reactions: A meta-analytic review. International Journal of Selection and Assessment, 17, 346-361.

United States Department of Agriculture and Economic Research Service (2020). https://data.ers. usda.gov/reports.aspx?ID=17827

Van Esch, P., Black, J. S., \& Ferolie, J. (2019). Marketing AI recruitment: The next phase in job application and selection. Computers in Human Behavior, 90, 215-222.

Vinokur, A. D., Pierce, P. F., Lewandowski-Romps, L., Hobfoll, S. E., \& Galea, S. (2011). Effects of war exposure on air force personnel's mental health, job burnout and other organizational related outcomes. Journal of Occupational Health Psychology, 16, 3-17.

Walton, G. M. (2014). The new science of wise psychological interventions. Current Directions in Psychological Science, 23, 73-82.

Watkins, E. R. (2008). Constructive and unconstructive repetitive thought. Psychological Bulletin, 134, 163-206.

Wiechmann, D., \& Ryan, A. M. (2003). Reactions to computerized testing in selection contexts. 
International Journal of Selection and Assessment, 11, 215-229.

Wharton, A. S. (1993). The affective consequences of service work: Managing emotions on the job. Work and Occupations, 20, 205-232.

World Health Organization (WHO, 2021). WHO Coronavirus (COVID-19) Dashboard. https://covid19.who.int/

Wouters, O. J., Shadlen, K. C., Salcher-Konrad, M., Pollard, A. J., Larson, H. J., Teerawattananon, Y., \& Jit, M. (2021). Challenges in ensuring global access to COVID-19 vaccines: Production, affordability, allocation, and deployment. The Lancet, 397, 13-19. 


\section{Footnotes}

${ }^{1}$ While interview anxiety focuses on anticipated threats, such as implications of doing poorly on the job interview and not getting the job, rumination is more present-oriented and in this case reflects a focus on what is happening with respect to the current pandemic (see Nolen-Hoeksema et al., 2008).

${ }^{2}$ To date, there have been 11 peer-reviewed studies of students conducting mock interviews, and one study of mock interviews in a field setting (Banki \& Latham, 2009). Only four studies have examined job applicants, three of which have examined students applying for interviews orchestrated via career counselling services at their respective Universities (Keenan, 1978; McCarthy \& Goffin, 2004; Stumpf et al., 1987), and one study of students applying for residence assistance positions (Schneider et al., 2019). A full list of these studies is available from the first author by request.

${ }^{3}$ The gender composition of our sample (52\% female) was similar to the gender composition of the AVI population $(51 \%$ female; $\chi 2(1)=8.88, p<0.01 ; \varnothing=0.01)$. With respect to age, respondents were seven years older $(\mathrm{m}=37.23, \mathrm{SD}=12.46)$ than non-respondents $(m=30.13, \mathrm{SD}=8.87 ; t(8,352)=$ 51.97, $p<0.01$, Cohen's $d=0.57)$. Meaningful differences were also found with respect to the ethnic representation of survey participants $\left(\chi^{2}(3)=686.97, p<0.01, \varnothing=0.82\right)$. Specifically, survey participants were less likely to be Asian ( $9 \%$ of survey participants, $17 \%$ of AVI population) and more likely to be White (51\% of survey participants, $40 \%$ of AVI population). Small differences were found for Blacks (21\% of survey participants, $19 \%$ of AVI population) and Hispanics (18\% of survey participants, $25 \%$ of AVI population). Survey participants also had significantly higher interview performance scores $(m=.53, S D=0.29)$ compared to the AVI population $(m=.51, S D=0.29)$, although this effect was small in magnitude $(t(1775)=3.33, p<0.01$, Cohen's $d=0.08)$.

${ }^{4}$ A complete validation report for the interview performance measure is available from the first author by request and demonstrates that this measure exhibits strong psychometric properties. In the majority of cases, interview and survey questions were aligned with the language in the country of origin.

${ }^{5}$ In addition to the two items used in our analysis, we also measured employees' fairness perceptions about the application and hiring process in general with three items: "I have been treated politely during the virtual job interview and selection process," "The recruiters have been considerate to me during the application and hiring process," and "The recruiters treated me with respect during the application and hiring process." Whether using this three-item scale as an alternative measure of perceived fairness or combining this three-item scale with the two perceived fairness items used in our analysis, our findings and conclusions remained the same. For parsimony and to be consistent with our theorizing, we limit the perceived fairness items to two items specifically pertaining to the virtual job interview itself.

${ }^{6} \mathrm{We}$ also conducted a robustness check by estimating the path model with multilevel modeling; all findings remained the same (multilevel modeling excluded organizations with fewer than 2 applicants from the data). For brevity and to preserve the largest sample size possible, we report results using the sandwich estimator below.

${ }^{7}$ We conducted confirmatory factor analysis (CFA) to examine whether our measures of COVID-19 rumination, COVID-19 exhaustion, interview anxiety, and perceived fairness captured distinct constructs. Results showed that the proposed four-factor model (loading the items onto four 
corresponding latent factors) fit the data well; $\chi^{2}(d f=84)=3282.10, \mathrm{CFI}=.94, \mathrm{TLI}=.93, \mathrm{RMSEA}=$ $.07, \mathrm{SRMR}=.03$. All standardized factor loadings were significant $(p \mathrm{~s}<.001)$. This model fit the data better than alternative three-factor models (loading items measuring two of the four variables onto one common latent factor), $\Delta \chi^{2} \mathrm{~s}[\Delta d f=3]$ ranged from 3636.91 to $12403.69, p \mathrm{~s}<.001$. These results suggest that our measures captured distinct constructs. In line with our path modeling analysis, the CFAs were conducted with the sandwich estimator to account for organizational-based clustering. As a robustness check, we conducted another set of CFAs without the sandwich estimator. The resulting four-factor model still fit the data well and was significantly better than any alternative three-factor or one-factor models. All robustness check results are available from the first author upon request.

${ }^{8} \mathrm{We}$ also tested two alternative models in which the orders of variables were reversed, such that AVI interview anxiety served as the antecedent. In the first model, interview anxiety was positioned as an antecedent of COVID-19 rumination, with COVID-19 exhaustion positioned as a second stage moderator of the outcome variables. While this model found that interview anxiety was positively related to rumination; rumination was not related to interview performance or recommendation intentions. Rumination was positively related to perceived fairness, which was the opposite to our expectation. Further, COVID-19 exhaustion did not emerge as a significant moderator. In the second post hoc analysis, interview anxiety was positioned as an antecedent of COVID-19 exhaustion, with COVID-19 rumination positioned as the second-stage moderator. Results indicated that while interview anxiety was positively related to COVID-19 exhaustion, and exhaustion in turn was significantly and negatively related to perceived fairness and recommendation intentions. However, COVID-19 exhaustion was also found to be positively related to interview performance, which is opposite of what we would expect. Further, COVID-19 rumination did not emerge as a significant moderator. With respect to the unexpected positive correlations, we note that they (1) theoretically did not form plausible predictions, and (2) empirically did not demonstrate a strong pattern in line with the zeroorder correlations (neither had a positive and significant zero-order correlation). Combined, these findings do not support reversing the order of constructs and help substantiate our conceptual model. Detailed results are available from the first author upon request.

${ }^{9}$ We also tested for a curvilinear effect between interview anxiety and performance. The quadratic term was negative, suggesting the shape of an inverted $\mathrm{U}$, but findings were not significant $(\gamma=-.003, p=$ $.61)$.

${ }^{10}$ We anticipate that virtual interview anxiety levels will be higher given that we are examining real applicants applying for actual positions in the midst of a pandemic (c.f., Chapman et al., 2005; Truxillo et al., 2009). In support of this proposition, the levels of anxiety we obtained $(m=2.89, S D=1.14)$ are significantly higher than Melchers et al. (2021), who examined 32 students undergoing a mock virtual interview prior to the pandemic and found average anxiety levels of $2.22(S D=.52 ; t=-2.94$, $\mathrm{df}=$ $8523, p<.01)$. There is also limited data on mean levels of applicant anxiety in actual face-to-face interview contexts prior to the pandemic. Specifically, McCarthy and Goffin (2004) obtained data on levels of interview anxiety among students applying for jobs and found average scores of $2.65(S D=$ $.79 ; N=182$ ) on a five-point scale. These levels are significantly lower than what was found in the current study $(m=2.89, S D=1.14 ; N=8,343 ; t=-2.94, \mathrm{df}=8523, p<.01)$. Stumpf et al. (1987) also obtained data on levels of anxiety among student applicants and found average scores of $1.97(S D=$ $.50, N=78)$, which were also significantly lower than those obtained in the current study $(t=-7.12$, df $=8419, p<.001)$. 
Table 1

Means, Standard Deviations, Correlations, and Reliabilities among Study Variables

\begin{tabular}{|c|c|c|c|c|c|c|c|c|c|c|c|c|c|}
\hline & Variables & Mean & $S D$ & 1 & 2 & 3 & 4 & 5 & 6 & 7 & 8 & 9 & 10 \\
\hline 1. & Age & 37.23 & 12.46 & -- & & & & & & & & & \\
\hline 2. & Gender & .52 & .50 & $-.09 * *$ & -- & & & & & & & & \\
\hline 3. & Location - EMEA & .12 & .33 & $-.07 * *$ & $-.05 * *$ & -- & & & & & & & \\
\hline 4. & Location - APAC & .10 & .30 & $-.15^{* *}$ & $-.03 * *$ & $-.12 * *$ & -- & & & & & & \\
\hline 5. & Race - Black & .21 & .41 & $-.06 * *$ & $.03 * *$ & $-.08 * *$ & $-.13 * *$ & -- & & & & & \\
\hline 6. & Race - Hispanic & .18 & .39 & $-.23 * *$ & $-.04 * *$ & $.03 *$ & $-.09 * *$ & $-.24 * *$ & -- & & & & \\
\hline 7. & Race - Asian & .09 & .29 & $-.22 * *$ & $-.02 *$ & $-.05 * *$ & $.65^{* *}$ & $-.17 * *$ & $-.16^{* *}$ & -- & & & \\
\hline 8. & Employment Status & .43 & .50 & $.04 * *$ & .01 & -.00 & $-.03 * *$ & .00 & $-.04 * *$ & -.02 & -- & & \\
\hline 9. & Telework Status & .42 & .49 & .01 & $.04 * *$ & $.09 * *$ & $.11 * *$ & $-.12 * *$ & $-.05^{*}$ & $.12 * *$ & -.19 & -- & \\
\hline 10. & Managerial Status & .21 & .40 & $.09 * *$ & $-.11 * *$ & $.13^{* *}$ & $.13^{* *}$ & $-.08 * *$ & $-.07 * *$ & $.13^{* *}$ & .12 & .13 & -- \\
\hline 11. & Employer Size & 10.46 & 2.02 & $-.14 * *$ & $-.06^{* *}$ & .02 & $.17^{* *}$ & .01 & $.10 * *$ & $.19^{* *}$ & $-.02 *$ & $-.16^{* *}$ & $-.06 * *$ \\
\hline 12. & Industry - Sales & .29 & .45 & $-.10 * *$ & $-.04 * *$ & $.06^{* *}$ & $-.15 * *$ & $-.07 * *$ & $.22 * *$ & $-.11 * *$ & $-.07 * *$ & $-.21 * *$ & -.04 \\
\hline 13. & Industry - Service & .22 & .41 & $-.02 *$ & $-.08 * *$ & -.02 & $.29 * *$ & $.13 * *$ & $-.08 * *$ & $.24 * *$ & $-.05 * *$ & $-.06^{*}$ & .04 \\
\hline 14. & Industry - Finance & .12 & .32 & $-.04 * *$ & $.02 *$ & -.02 & $-.03 * *$ & -.01 & -.02 & $.02 *$ & $.03 * *$ & $.15^{* *}$ & -.01 \\
\hline 15. & Industry - Public administration & .10 & .30 & $.10 * *$ & $.13^{* *}$ & $-.10 * *$ & $-.08 * *$ & $-.05 * *$ & $-.09 * *$ & $-.08 * *$ & $.08 * *$ & $.21 * *$ & -.02 \\
\hline 16. & Industry - Manufacturing & .10 & .29 & $.04 * *$ & $-.11 * *$ & .00 & $.04 * *$ & $-.03 * *$ & $-.03 *$ & $-.03 * *$ & .00 & $-.04 *$ & .00 \\
\hline 17. & COVID-19 Rumination & 1.76 & 1.03 & $-.14 * *$ & -.01 & $-.02 *$ & $.10 * *$ & .02 & $.03 * *$ & $.13 * *$ & .01 & -.03 & .02 \\
\hline 18. & COVID-19 Exhaustion & 2.17 & 1.14 & $-.16^{* *}$ & .02 & $.04 * *$ & $.16^{* *}$ & $-.10 * *$ & -.01 & $.18^{* *}$ & .01 & $.11^{* *}$ & .02 \\
\hline 19. & Interview Anxiety & 2.89 & 1.14 & $-.10 * *$ & $.08 * *$ & $.04 * *$ & $.08 * *$ & $-.05 * *$ & .01 & $.08 * *$ & -.01 & .02 & -.03 \\
\hline 20. & Interview Performance & .53 & .29 & $.06^{*}$ & .00 & -.08 & .01 & $-.11 * *$ & $-.06^{*}$ & .02 & .04 & .07 & .03 \\
\hline 21. & Perceived Fairness & 4.50 & .78 & $-.05 * *$ & -.00 & $-.06 * *$ & .01 & $.09 * *$ & $.04 * *$ & .00 & -.02 & $-.09 * *$ & -.03 \\
\hline 22. & Recommendation Intentions & 9.29 & 1.37 & $.02 *$ & $.05^{* *}$ & -.01 & $-.05 * *$ & $.05 * *$ & $.07 * *$ & $-.05 * *$ & $-.02 *$ & $-.07 * *$ & -.00 \\
\hline 23. & COVID-19 Duration ${ }^{\mathrm{a}}$ & 102.32 & 25.99 & .01 & .02 & $-.06 * *$ & -.01 & -.01 & .00 & -.00 & .01 & $-.09 * *$ & -.00 \\
\hline 24. & COVID-19 Cases ${ }^{\mathrm{ab}}$ & 7.52 & 5.40 & .02 & .01 & -- & -- & $.05 * *$ & -.02 & -.01 & $.04 * *$ & -.02 & .03 \\
\hline 25. & COVID-19 Deaths ${ }^{\text {ab }}$ & .29 & .37 & $.04 * *$ & -.02 & -- & -- & $.06^{* *}$ & $-.08 * *$ & $.03 *$ & $.04^{* *}$ & $.05^{*}$ & .04 \\
\hline
\end{tabular}


Table 1 (Cont.)

Means, Standard Deviations, Correlations, and Reliabilities

\begin{tabular}{|c|c|c|c|c|c|c|c|c|c|c|c|c|c|c|c|}
\hline & Variables & 11 & 12 & 13 & 14 & 15 & 16 & 17 & 18 & 19 & 20 & 21 & 22 & 23 & 24 \\
\hline 11. & Employer Size & -- & & & & & & & & & & & & & \\
\hline 12. & Industry - Sales & $.26^{* *}$ & -- & & & & & & & & & & & & \\
\hline 13. & Industry - Service & $.15^{* *}$ & $-.34 * *$ & -- & & & & & & & & & & & \\
\hline 14. & Industry - Finance & .01 & $-.23 * *$ & $-.19 * *$ & -- & & & & & & & & & & \\
\hline 15. & Industry - Public administration & $-.41 * *$ & $-.21 * *$ & $-.17 * *$ & $-.12 * *$ & -- & & & & & & & & & \\
\hline 16. & Industry - Manufacturing & $-.07 * *$ & $-.21 * *$ & $-.17 * *$ & $-.12 * *$ & $-.11 * *$ & -- & & & & & & & & \\
\hline 17. & COVID-19 Rumination & $.07 * *$ & .02 & $.06^{* *}$ & $-.03 * *$ & -.01 & $-.05^{* *}$ & $(.79)$ & & & & & & & \\
\hline 18. & COVID-19 Exhaustion & .02 & $-.07 * *$ & $.03 * *$ & $.04 * *$ & $.05 * *$ & $-.04 * *$ & $.38^{* *}$ & $(.89)$ & & & & & & \\
\hline 19. & Interview Anxiety & .02 & -.01 & -.01 & .01 & .00 & .02 & $.22 * *$ & $.36^{* *}$ & $(.89)$ & & & & & \\
\hline 20. & Interview Performance & $-.09 *$ & $-.09 *$ & .07 & -.06 & $-.07 * *$ & -.06 & -.01 & .04 & $-.09 * *$ & -- & & & & \\
\hline 21. & Perceived Fairness & $.08^{* *}$ & $.05 * *$ & $.05^{* *}$ & $-.02 *$ & $-.07 * *$ & $-.02 *$ & $-.04 * *$ & $-.17 * *$ & $-.35 * *$ & .01 & $(.79)^{\mathrm{c}}$ & & & \\
\hline 22. & Recommendation Intentions & $.06^{* *}$ & $.07 * *$ & $-.05 * *$ & .01 & $-.07 * *$ & .01 & $-.08 * *$ & $-.18^{* *}$ & $-.20 * *$ & -.02 & $.47 * *$ & -- & & \\
\hline 23. & COVID-19 Duration ${ }^{a}$ & .02 & $.06^{* *}$ & $-.08 * *$ & .01 & .01 & -.01 & -.00 & .01 & .02 & -.04 & .00 & .02 & -- & \\
\hline 24. & COVID-19 Cases ${ }^{\text {ab }}$ & $.03 *$ & $-.03 * *$ & $.03 *$ & $.05^{* *}$ & -.01 & -.02 & .00 & .01 & .02 & .01 & -.01 & .00 & $.60 * *$ & -- \\
\hline 25. & COVID-19 Deaths ab & .00 & $-.12 * *$ & $.08^{* *}$ & $.08 * *$ & -.02 & .01 & -.01 & $.03 * *$ & .01 & .04 & -.01 & $-.03 *$ & $.16^{*}$ & $.72 * *$ \\
\hline
\end{tabular}

Note. Pair-wise $N \mathrm{~s}=1,775-8,343$. Cronbach's alphas are presented in the parentheses along the diagonal when applicable. Age, gender, and race were predicted by computer-based algorithms (see Appendix A for details). Age of the applicant was in years. Gender $=1$ for female applicants and 0 for male applicants. Two dummy variables were created to represent the locations where participants took the interview, with the AMER area being the reference group. AMER = North, Central, South America; EMEA = Europe, Middle East, Africa; APAC = Asia Pacific, Japan. Three dummy variables were created to represent Black, Hispanic, or Asian respondents, with White $=0$ respondents being the reference group. Employment status $=1$ for applicants who were employed at the time of interview, and 0 for those who were not employed. Telework status $=1$ for applicants who worked from home at the time of interview, and 0 for those who did not work from home. Managerial status $=1$ for applicants who worked on a managerial position at the time of interview, and 0 for those who were entry-level employees. Employer size was the number of employees in the employer, transformed with a logarithm function. Five dummy variables were created to represent 6 industry sectors to which the employers belonged. COVID-19 duration = the number of days between March 11, 2020 when the COVID-19 outbreak was declared as a pandemic by the World Health Organization and the applicants' interview date; COVID-19 cases = area cumulative COVID cases (/1,000 people) in the state/province on the interview date; COVID-19 deaths $=$ area cumulative COVID deaths (/1,000 people) in the state/province on the interview date. ${ }^{\text {a }}$ \# of COVID cases and deaths were divided by population in that state/province. ${ }^{\mathrm{b}}$ These correlations with other variables were based on a sample of 6,136 participants who took the virtual job interview in the United States or Canada. Because all participants in this subsample took the interview in AMER area, there was no correlation between these two variables and location (EMEA/APAC). ${ }^{\mathrm{c}}$ Reliability computed with Spearman-Brown formula for two-item scale. $* p<.05, * * p<.01$, two-tailed. 
Table 2

Unstandardized Path Modeling Results

\begin{tabular}{|c|c|c|c|c|c|c|c|c|c|c|c|c|}
\hline \multirow[b]{2}{*}{ Variables } & \multicolumn{3}{|c|}{ Interview Anxiety } & \multicolumn{3}{|c|}{ Interview Performance } & \multicolumn{3}{|c|}{ Perceived Fairness } & \multicolumn{3}{|c|}{ Intention to Recommend } \\
\hline & Estimate & $S E$ & $p$ & Estimate & $S E$ & $p$ & Estimate & $S E$ & $p$ & Estimate & $S E$ & $p$ \\
\hline Intercept & $2.88 * *$ & .02 & $<.001$ & $.62 * *$ & .04 & $<.001$ & $5.18 * *$ & .05 & $<.001$ & $9.89 * *$ & .05 & $<.001$ \\
\hline \multicolumn{13}{|l|}{ Control variables } \\
\hline Age & $-.00 * *$ & .00 & .01 & .00 & .00 & .99 & $-.00 * *$ & .00 & $<.001$ & $.00 *$ & .00 & .02 \\
\hline Gender & $.17 * *$ & .03 & $<.001$ & .00 & .01 & .78 & $.04 *$ & .02 & .04 & $.21 * *$ & .03 & $<.001$ \\
\hline Location - EMEA & $.14 * *$ & .04 & $<.001$ & $-.11 *$ & .05 & .02 & $-.08 *$ & .04 & .02 & -.00 & .05 & .94 \\
\hline Location - APAC & $.11 *$ & .06 & .04 & -.04 & .07 & .57 & .07 & .05 & .17 & -.04 & .07 & .57 \\
\hline Race - Black & -.04 & .05 & .35 & $-.12 * *$ & .02 & $<.001$ & $.13 * *$ & .02 & $<.001$ & $.18 * *$ & .03 & $<.001$ \\
\hline Race - Hispanic & -.00 & .03 & .92 & $-.06 * *$ & .02 & .001 & $.09 * *$ & .02 & $<.001$ & $.28 * *$ & .03 & $<.001$ \\
\hline Race - Asian & -.04 & .07 & .52 & -.03 & .06 & .63 & .04 & .04 & .32 & .11 & .08 & .14 \\
\hline Employment status & -.03 & .04 & .35 & .03 & .03 & .22 & -.04 & .04 & .38 & -.09 & .07 & .18 \\
\hline Telework status & -.04 & .04 & .36 & $.05^{*}$ & .02 & .02 & $-.09 * *$ & .03 & .001 & $-.12 *$ & .05 & .01 \\
\hline Managerial status & -.09 & .05 & .07 & .00 & .04 & .95 & -.02 & .04 & .69 & .09 & .06 & .14 \\
\hline Employer size & .00 & .01 & .99 & $-.02 *$ & .01 & .02 & $.02 *$ & .01 & .01 & $.03 *$ & .01 & .01 \\
\hline Industry - Sales & .03 & .07 & .65 & $-.11 *$ & .05 & .02 & .01 & .04 & .70 & .06 & .05 & .29 \\
\hline Industry - Service & -.03 & .07 & .66 & -.03 & .05 & .54 & .02 & .04 & .60 & $-.17 * *$ & .06 & .004 \\
\hline Industry - Finance & .05 & .09 & .61 & $-.16^{* *}$ & .05 & .002 & -.02 & .04 & .69 & .06 & .06 & .34 \\
\hline Industry - Public administration & -.01 & .09 & .96 & $-.25 * *$ & .06 & $<.001$ & -.05 & .08 & .52 & -.17 & .17 & .32 \\
\hline Industry - Manufacturing & .17 & .09 & .06 & -.16 & .08 & .06 & -.02 & .06 & .76 & .08 & .07 & .25 \\
\hline COVID-19 duration & .00 & .00 & .32 & -.00 & .00 & .29 & -.00 & .00 & .86 & .00 & .00 & .30 \\
\hline \multicolumn{13}{|c|}{ Predictors, interaction term, and mediator } \\
\hline COVID-19 rumination & $.10^{* *}$ & .02 & $<.001$ & -.001 & .01 & .94 & $.03 * *$ & .01 & .001 & .01 & .02 & .68 \\
\hline COVID-19 exhaustion & $.31 * *$ & .01 & $<.001$ & $.02 *$ & .01 & .02 & $-.05 * *$ & .01 & $<.001$ & $-.12 * *$ & .02 & $<.001$ \\
\hline $\begin{array}{l}\text { COVID-19 rumination } \times \\
\text { COVID exhaustion }\end{array}$ & $.03 * *$ & .01 & .004 & .00 & .01 & .65 & .01 & .01 & .26 & -.03 & .01 & .07 \\
\hline Interview anxiety & & & & $-.03 * *$ & .01 & .01 & $-.23 * *$ & .02 & $<.001$ & $-.20 * *$ & .02 & $<.001$ \\
\hline$R^{2} / \Delta R^{2}$ & \multicolumn{3}{|c|}{$15 \% * * / 13 \% * *$} & $11 \%$ & $* * / 20$ & & \multicolumn{3}{|c|}{$15 \% * * / 13 \% * *$} & \multicolumn{3}{|c|}{$8 \% * * / 5 \% * *$} \\
\hline
\end{tabular}

Note. $N=8,343$. Unstandardized coefficients are reported. $\Delta R^{2}$ were computed by comparing the estimated (full) model with a baseline model that only contained control variables as predictors. Race was coded 1 if the predicted race was positive for each one listed and 0 if not. COVID-19 duration $=$ the number of days between March 11 , 2020 when COVID-19 outbreak was declared as a pandemic by the World Health Organization and the applicants' interview date. ${ }^{*} p<.05,{ }^{* *} p<.01$, two-tailed. 
Table 3

Moderated Mediation Effects

Hypothesized Effects

Estimate

95\% Confidence Interval

Interview performance as the dependent variable (Hypothesis 4)

Moderated mediation effect ${ }^{\text {a }}$

Conditional indirect effect of COVID-19 rumination on interview performance

At high COVID-19 exhaustion (+1 SD)

At low COVID-19 exhaustion (-1 SD)

Difference between the two conditional indirect effects

Perceived fairness as the dependent variable (Hypothesis 5a)

Moderated mediation effect ${ }^{\text {a }}$

Conditional indirect effect of COVID-19 rumination on perceived fairness

At high COVID-19 exhaustion (+1 SD)

At low COVID-19 exhaustion (-1 SD)

Difference between the two conditional indirect effects

\section{Recommendation Intentions as the dependent variable (Hypothesis $5 b$ )}

Moderated mediation effect ${ }^{\text {a }}$

Conditional indirect effect of COVID-19 rumination on recommendation intentions

At high COVID-19 exhaustion (+1 SD)

At low COVID-19 exhaustion (-1 SD)

Difference between the two conditional indirect effects

$-.001 \quad[-.002,-.0002]$

$-.004 \quad[-.007,-.001]$

$-.002 \quad[-.005,-.0002]$

$-.002 \quad[-.004,-.0004]$

$-.007 \quad[-.012,-.002]$

$-.031 \quad[-.038,-.025]$

$-.015 \quad[-.025,-.004]$

$-.016 \quad[-.027,-.005]$

$-.006 \quad[-.011,-.002]$

$-.026 \quad[-.034,-.019]$

$-.013 \quad[-.022,-.004]$

$-.013 \quad[-.024,-.004]$

Note. Confidence intervals were obtained using the Monte Carlo simulation procedure with 20,000 bootstrap repetitions. An indirect effect is significant when the $95 \%$ confidence interval does not contain zero.

a The moderated mediation effect was computed by multiplying the interactive effect of COVID-19 rumination and COVID-19

exhaustion on interview anxiety with the effect of interview anxiety on the corresponding dependent variable. 


\section{Figure 1}

Conceptual Model

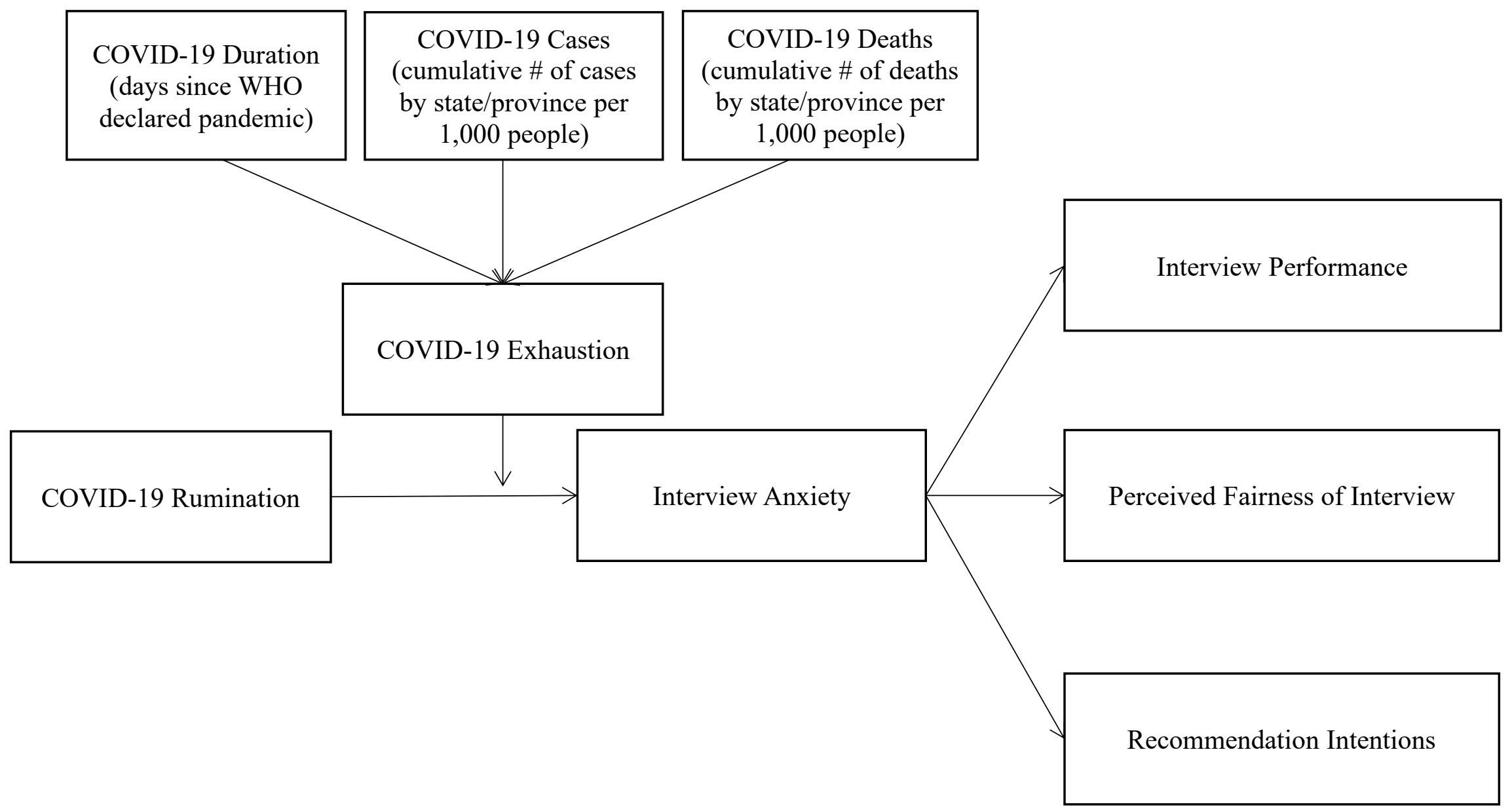




\section{Figure 2}

Unstandardized Path Analysis Results from the Entire Sample $(n=8,343)$

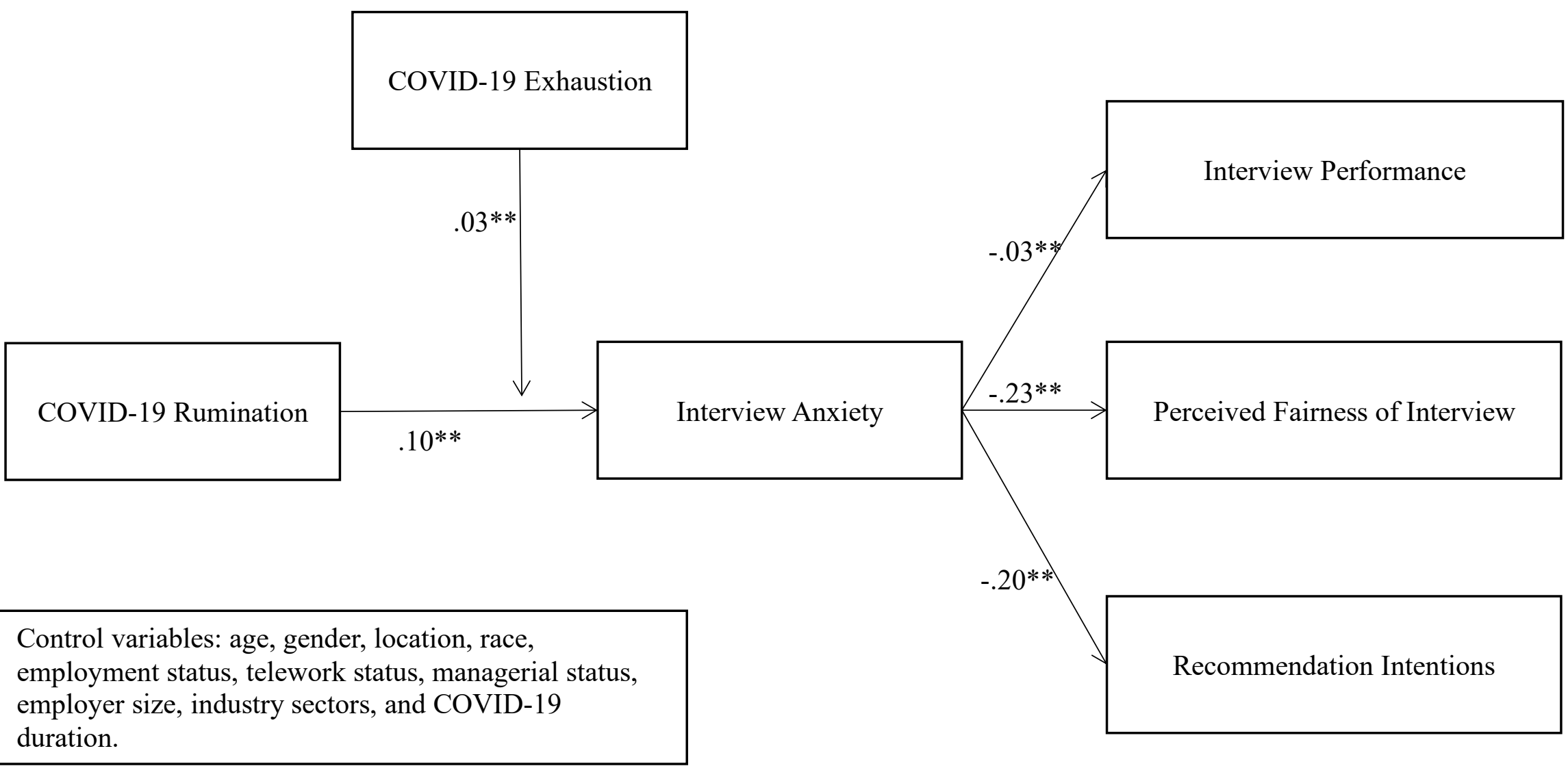

Note. $N=8,343$. Unstandardized path model coefficients are reported. For brevity, all direct effects as well as the effects of control variables are not reported in this figure, but are reported in Table $2{ }^{*} p<.05, * * p<.01$, two-tailed. 


\section{Figure 3}

Unstandardized Path Analysis Results from the Subsample $(n=6,136)$

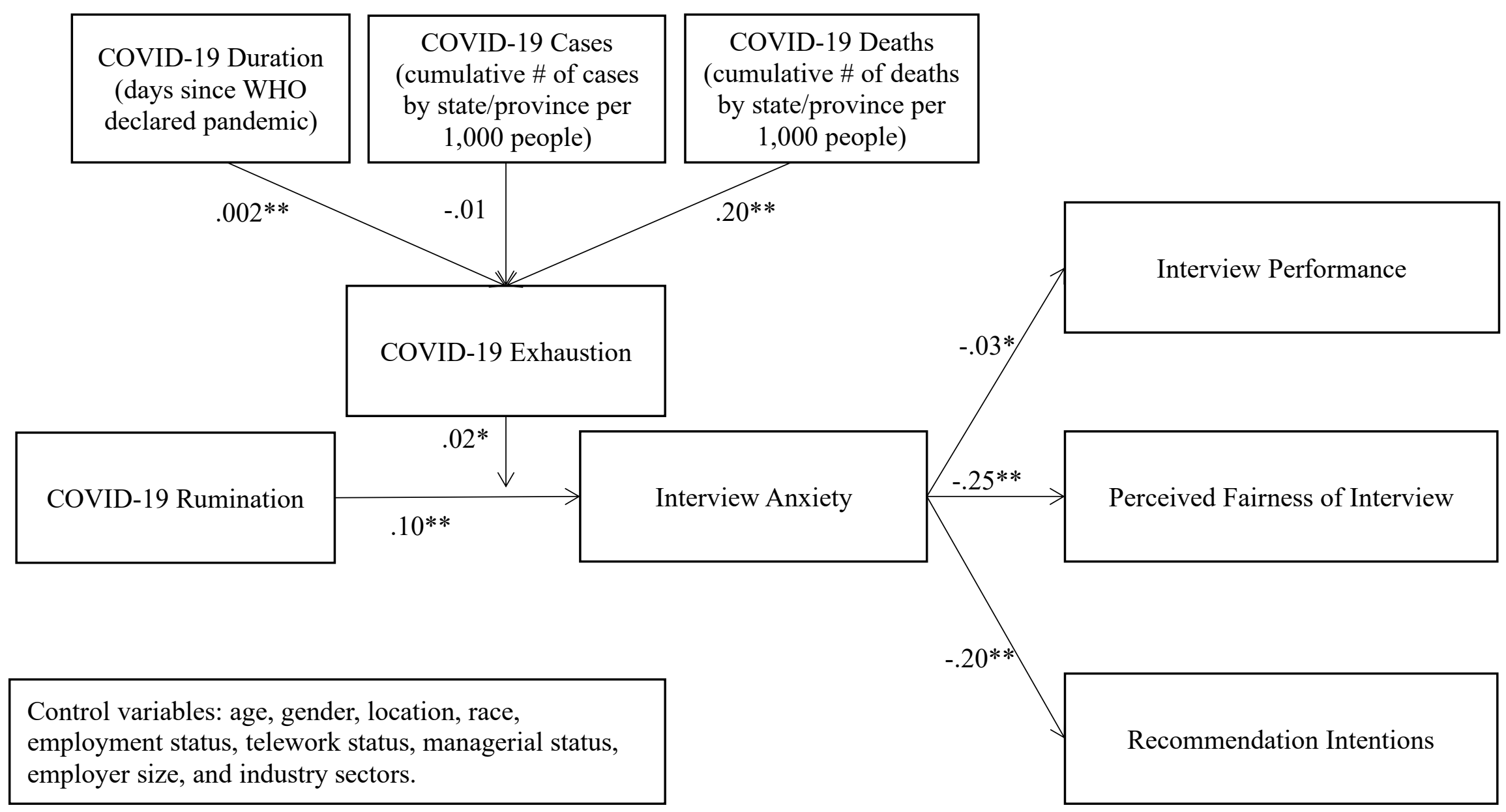

Note. $n=6,136$ (participants from US and Canada only). Unstandardized path model coefficients are reported. For brevity, all direct effects as well as the effects of control variables are modeled but are not reported in this figure. Duration, cases, and deaths were gathered based on the date of the interview. Complete results are available upon request to the first author. ${ }^{*} p<.05, * * p<.01$, twotailed. 


\section{Figure 4}

The Moderating Effect of COVID-19 Exhaustion on the Relationship Between COVID-19 Rumination and Interview Anxiety

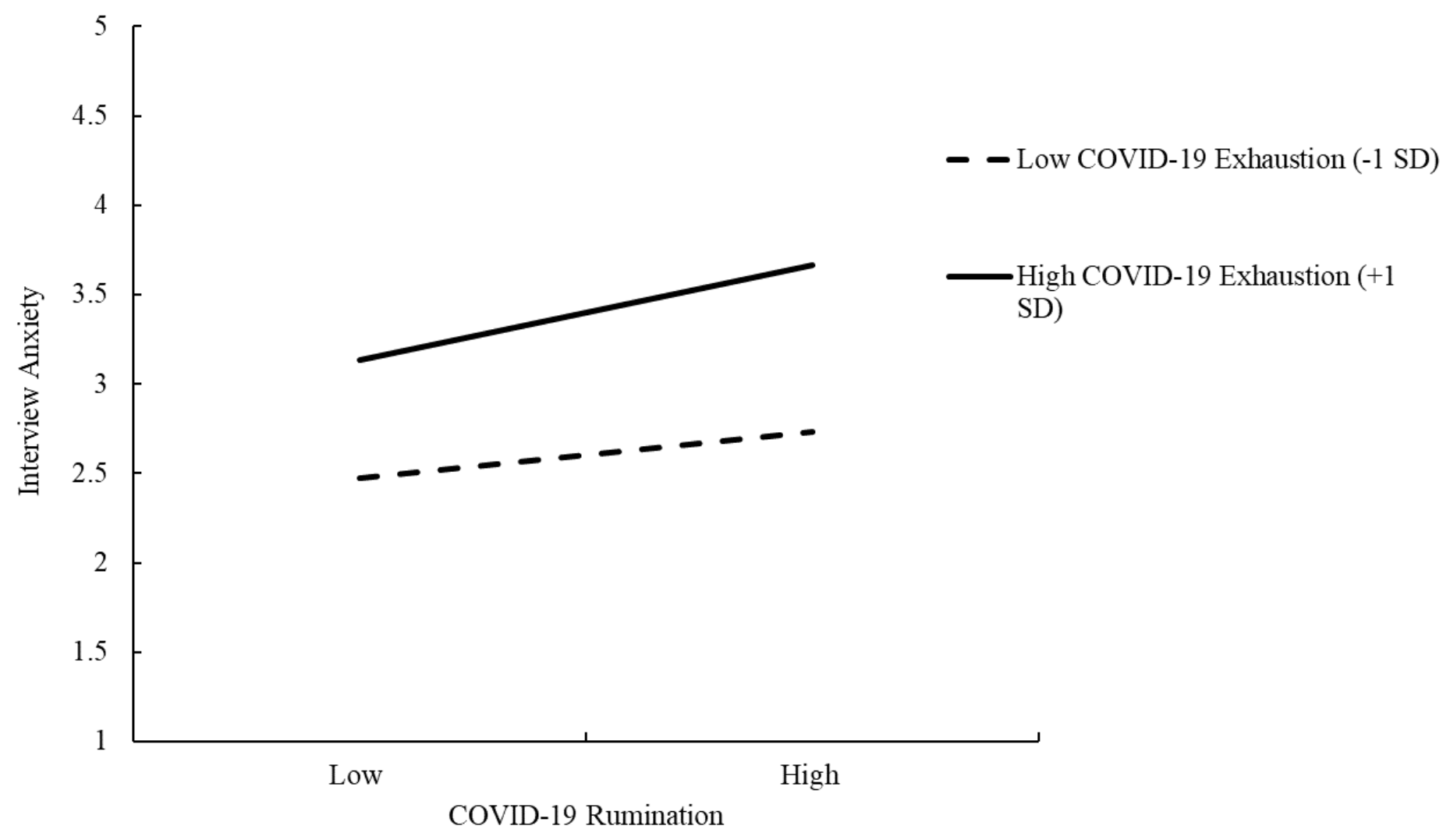




\section{Appendix A: Measurement Details of Control Variables}

Job applicants' age (in years), gender $(1=$ female; $0=$ male), and race (White, Black, Hispanic, and Asian) were predicted by a proprietary demographic prediction algorithm, which was developed by the recruiting-technology company. The company used a publicly available database of over 500,000 face images (https://data.vision.ee.ethz.ch/cvl/rrothe/imdb-wiki/) to develop the algorithm predicting age and gender, and utilized self-reported data to develop the algorithm predicting race. According to the recruiting-technology company, the classification accuracy of this demographic prediction algorithm was $94 \%, 99 \%$, and $87 \%$ for predicting age, gender, and race, respectively. In our analysis, we created three dummy variables to represent Black, Hispanic, and Asian job applicants, with the majority racial group (i.e., White) being the reference group. The recruiting-technology company obtained the job applicants' consent before using a thumbnail image of their virtual job interview video and retrieving their age, gender, and race information solely for research purposes. In terms of interview questions, applicants were presented with an average of 5.80 questions $(\mathrm{SD}=2.89)$. While there was a wide variety of question types, the majority $(80 \%$ - $90 \%)$ were past behavior situational questions, and some $(10 \%$ to $20 \%)$ were situational interview questions.

We also controlled for the location where participants took the virtual job interview (these data were provided by the recruiting-technology company after acquiring employers' and applicants' agreement). Specifically, our study contained participants in a total of 93 countries, among whom the vast majority (74\%) took the virtual job interview in United States or Canada. According to the geographic classification, the location of our participants was broadly classified into three categories: AMER (North, Central, and South America; 78\%), EMEA (Europe, the Middle East, and Africa; 12\%), and APAC (Asia Pacific and Japan; 10\%). In our analysis, we controlled for location of virtual job interview by creating two dummy variables to represent EMEA and APAC, with AMER (the majority) being the reference group. The overall pattern of findings does not change if we consider only participants in the AMER area or only participants from the United States or Canada.

We also asked the participants to indicate whether they were employed or not at the time of interview, and controlled for the effect of employment status $(1=$ employed; $0=$ not employed). Additionally, we asked participants to indicate whether they were working from home at the time of interview and controlled for telework status $(1=$ working from home; $0=$ not working from home). We also asked participants whether they worked in a managerial position in their current job at the time of the interview $(1=$ yes, $0=$ no), and this variable was controlled for in our analysis as well. Finally, we controlled for COVID-19 duration, which is the number of days between March 11, 2020 when the COVID-19 outbreak was declared as a pandemic by the World Health Organization and the applicant's interview date.

In terms of the prospective employers' characteristics, we controlled for the employer size (i.e., the number of employees working in the organization). A logarithm transformation was used to rescale employer size due to its non-normal distribution. We also controlled for the industry sector that the employer belonged to. Specifically, employers in our dataset were in 6 different industry sectors, including sales $(29 \%)$, service $(22 \%)$, finance $(12 \%)$, manufacturing and construction $(10 \%)$, public administration (10\%), or others. Thus, 5 dummy variables were created to represent the 6 industry sectors in our data analysis. Data on interview date, employer size, and employer industry sectors were obtained from the recruiting-technology company after acquiring employers' agreement. 


\section{Appendix B: Measures of Focal Variables}

\begin{tabular}{|c|c|}
\hline Variable names & Items \\
\hline $\begin{array}{l}\text { COVID-19 } \\
\text { rumination }\end{array}$ & $\begin{array}{l}\text { Please indicate the extent to which you agree with the following items. ( } 1= \\
\text { strongly disagree; } 5=\text { strongly agree) } \\
\text { During the virtual job interview, I thought about something related to COVID- } \\
19 . \\
\text { During the virtual job interview, my mind was focusing on COVID-19 related } \\
\text { issues. } \\
\text { During the virtual job interview, I thought about members of my family and/or } \\
\text { friends with respect to COVID-19. }\end{array}$ \\
\hline $\begin{array}{l}\text { COVID-19 } \\
\text { exhaustion }\end{array}$ & $\begin{array}{l}\text { Please indicate the extent to which you agree with the following items. }(1= \\
\text { strongly disagree; } 5=\text { strongly agree) } \\
\text { As a result of COVID-19, I feel emotionally drained. } \\
\text { As a result of COVID-19, I feel used up. } \\
\text { As a result of COVID-19, I feel burned out. } \\
\text { As a result of COVID-19, I feel fatigued/tired. }\end{array}$ \\
\hline Interview anxiety & $\begin{array}{l}\text { Please indicate the extent to which you agree with the following items. ( } 1 \text { = } \\
\text { strongly disagree; } 5 \text { = strongly agree) } \\
\text { During the virtual job interview, I was nervous. } \\
\text { During the virtual job interview, I experienced anxiety. } \\
\text { During the virtual job interview, I felt worried about my performance. } \\
\text { During the virtual job interview, I thought about how poorly I was doing. } \\
\text { During the virtual job interview, I found myself thinking of the consequences of } \\
\text { failing. } \\
\text { During the virtual job interview, I was overwhelmed by thoughts of performing } \\
\text { poorly. }\end{array}$ \\
\hline Perceived fairness & $\begin{array}{l}\text { Please indicate the extent to which you agree with the following items. }(1= \\
\text { strongly disagree; } 5=\text { strongly agree) } \\
\text { I believe that the virtual job interview was fair. } \\
\text { I felt good about the way the virtual job interview was conducted and } \\
\text { administered. }\end{array}$ \\
\hline $\begin{array}{l}\text { Recommendation } \\
\text { Intentions }\end{array}$ & $\begin{array}{l}\text { Based on the virtual job interview experience you just had, how likely are you to } \\
\text { recommend }<<\text { Employer's Name }>>\text { to a friend or colleague? }(0=\text { not at all } \\
\text { likely, } 10=\text { extremely likely) }\end{array}$ \\
\hline
\end{tabular}

